\title{
Spotlight on Alkali Metals: The Structural Chemistry of Alkali Metal Thallides
}

\author{
Stefanie Gärtner $(D)$ \\ Central Analytics, X-ray Crystallography Department, Faculty of Chemistry and Pharmacy, University of \\ Regensburg, 93040 Regensburg, Germany; Stefanie.gaertner@ur.de; Tel.: +49-941-943-4446
}

Received: 5 October 2020; Accepted: 31 October 2020; Published: 7 November 2020

\begin{abstract}
Alkali metal thallides go back to the investigative works of Eduard Zintl about base metals in negative oxidation states. In 1932, he described the crystal structure of $\mathrm{NaTl}$ as the first representative for this class of compounds. Since then, a bunch of versatile crystal structures has been reported for thallium as electronegative element in intermetallic solid state compounds. For combinations of thallium with alkali metals as electropositive counterparts, a broad range of different unique structure types has been observed. Interestingly, various thallium substructures at the same or very similar valence electron concentration (VEC) are obtained. This in return emphasizes that the role of the alkali metals on structure formation goes far beyond ancillary filling atoms, which are present only due to charge balancing reasons. In this review, the alkali metals are in focus and the local surroundings of the latter are discussed in terms of their crystallographic sites in the corresponding crystal structures.
\end{abstract}

Keywords: thallide; alkali metal; X-ray crystal structure; Zintl phases

\section{Introduction}

In 1932, E. Zintl and W. Dullenkopf reported on the crystal structure determination of sodium thallide NaTl [1]. They completed their publication with the statement that, in case of a base metal, the formed structure type does not correlate with the average number of valence electrons per atom (VEC) according to the prevously introduced rules by Hume-Rothery [2], Westgren, and Phragmen [3]. This set a milestone in intermetallic chemistry and was the birth of polar intermetallic compounds, including metal-metal bonding (i.e., Zintl phases) [4-9] which perceive continually increasing interest in materials science [10]. In general, the combination of an electropositive and a rather electronegative metal right to the Zintl border (between group 13 and group 14 in the periodic system of elements), results in the formation of polyanionic salts [11-13]. By assuming a complete electron transfer from the electropositive to the more electronegative element, a modified valence electron concentration per p-block metal is calculated $\left(\mathrm{VEC}_{\text {Zintl }}\right)$, which, in combination with the $8-\mathrm{N}$ rule, gives the number of bonds of the electronegative element $[9,14,15]$. This model works very well for elements right to the Zintl border, but interestingly, with $\mathrm{NaTl}$, this concept was demonstrated for the first time by describing a compound of an element, which is left to this imaginary line. Its position at the frontier between metallic and salt-like materials makes thallium a very interesting metal concerning its structural chemistry in formal negative oxidation states [16-18]. Binaries of thallium and lithium, sodium, or potassium were recently summarized in terms of the respective phase diagrams [19]. Thümmel and Klemm reported investigations on the formed binaries of the heavier congeners, rubidium and cesium, in 1970 [20]. Reviews dealing with the Zintl compounds of the p-block elements [18,21,22] also include part of the alkali metal thallides, but they usually focus on the very versatile and interesting thallide substructures. However, the role of the involved alkali metals goes far beyond a classical cation which is present only for charge balancing reasons [23]. For example, the simple binaries $\mathrm{ATl}(\mathrm{A}=\mathrm{Li}, \mathrm{Na}$, $\mathrm{K}, \mathrm{Cs}$ ) feature different structure types and thallium substructures depending on the involved alkali 
metal (see Section 5.1) [24]. It seems to be worth having a closer look at the hitherto reported alkali metal thallides by drawing special attention to the alkali metals. Corbett et al. started to investigate the role of mixed alkali metals in thallide compounds and for the first time described the observed effects in the compound $\mathrm{Na}_{2} \mathrm{~K}_{21} \mathrm{Tl}_{19}$ (see Section 5.3). A small number of ternary compounds involving sodium and a heavier congener were reported subsequently. There are also known more complex systems like ternary compounds involving lighter group 13 elements (Ga, In) [25-28], elements from the d-block $[29,30]$ or thallide oxo compounds [31-33], but in this review the focus is set on the most simple combination of alkali metal and thallium, in order to point out structural effects of different alkali metals.

In general, all alkali metal thallide compounds, which will be discussed in the following, have been obtained experimentally by the respective groups by applying classical solid state techniques. To get an overview of the alkali metal thallide compounds, a map is arranged (Figure 1) in which the values of the averaged alkali metal radii are used as the ordinate; the abscissa is given by the values of the alkali metal proportion of the corresponding structure. The green areas highlight the parts of the diagram, where one structure type is known for different alkali metals. In contrast, there are structure types, which are unique for a certain alkali metal. For example, at a VEC of approximately 2.33, $\mathrm{K}_{49} \mathrm{Tl}_{108}$ is reported, whereas for rubidium and cesium this structure type could not yet be realized but instead $\mathrm{A}_{15} \mathrm{Tl}_{27}(\mathrm{~A}=\mathrm{Rb}, \mathrm{Cs})$ is known (see Section 3).

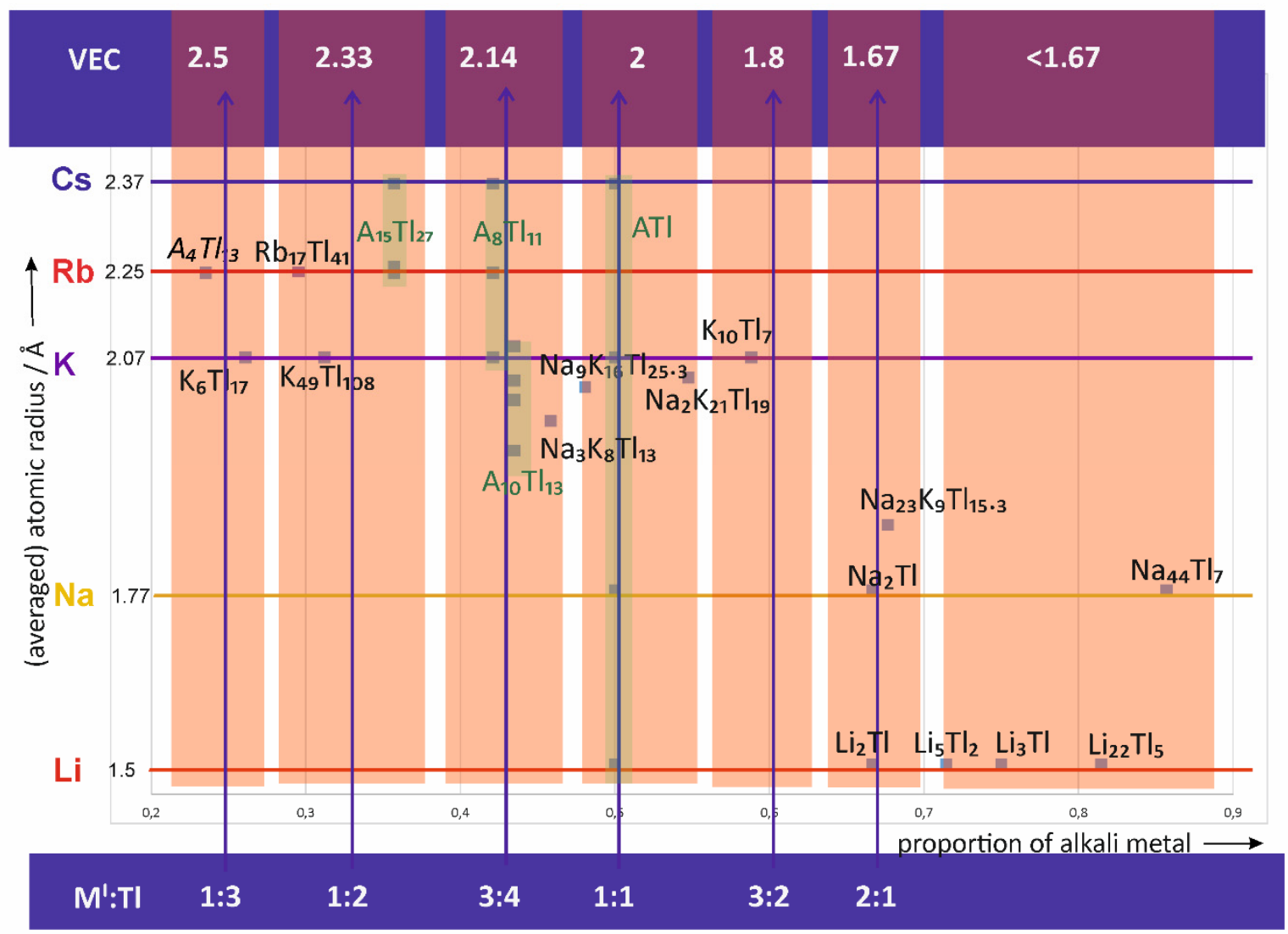

Figure 1. General map of the so far reported alkali metal thallides in dependence of their proportion and size of the involved of alkali metal(s). Areas of approximant ideal combinations $\mathrm{M}^{\mathrm{I}}: \mathrm{Tl}$ are highlighted and the corresponding valence electron concentration (VEC) is given.. For $\mathrm{A}_{4} \mathrm{Tl}_{13}(\mathrm{~A}=\mathrm{Rb}, \mathrm{Cs})$ no structural data is available. The structural family $\mathrm{A}_{15} \mathrm{Tl}_{27}$ includes the reported compounds $\mathrm{Rb}_{15} \mathrm{Tl}_{27}$, $\mathrm{Rb}_{14} \mathrm{CsTl}_{27}$ and $\mathrm{Cs}_{15} \mathrm{Tl}_{27} \cdot \mathrm{A}_{8} \mathrm{Tl}_{11}$ binary phases are known for $\mathrm{K}_{8} \mathrm{Tl}_{11}, \mathrm{Rb}_{8} \mathrm{Tl}_{11}$ and $\mathrm{Cs}_{8} \mathrm{Tl}_{11}$. The reported ternary $\mathrm{A}_{10} \mathrm{Tl}_{13}$ phases follow the formula $\mathrm{Na}_{4} \mathrm{~A}_{6} \mathrm{Tl}_{13}$ where $\mathrm{A}=\mathrm{K}, \mathrm{Rb}$ Cs. Binary ATl is known for $\mathrm{A}=\mathrm{Li}, \mathrm{Na}, \mathrm{K}, \mathrm{Cs}$. 
In the following, the seven different areas within this diagram (red) are discussed, beginning on the left hand side where naturally the compounds with low valence electron concentrations and high thallium content are located. In general, the overall composition given for the respective materials differs from the approximant ideal relation and emphasizes other effects than electron concentration for structure formation. Therefore, special attention will be drawn at the (extended) local environment of the alkali metals in the different alkali metal thallides based on the different crystallographic sites (Wyckoff positions) of the alkali metals in the respective published crystal structures.

\section{Atomic Ratio $\mathbf{M}^{\mathrm{I}}: \mathrm{Tl}$ Approximately $1: 3$}

In the area of $\mathrm{M}^{\mathrm{I}}: \mathrm{Tl} 1: 3$, the structural information of solely one compound, $\mathrm{K}_{6} \mathrm{Tl}_{17}$ [34], is reported in the literature. $\mathrm{A}_{4} \mathrm{Tl}_{13}(\mathrm{~A}=\mathrm{Rb}, \mathrm{Cs})$ is mentioned by Corbett et al. [35], but detailed structural information is not provided.

$\mathrm{K}_{6} \mathrm{Tl}_{17}$

$\mathrm{K}_{6} \mathrm{Tl}_{17}$ [34] represents the thallium richest alkali metal thallide compound of which a crystal structure has been reported so far. $\mathrm{K}_{6} \mathrm{Tl}_{17}$ features a VEC of 2.48 and crystallizes in the space group $\mathrm{Cccm}$. The compound consists of two crystallographically independent $\mathrm{Tl}_{12}$ units and additional $\mathrm{Tl}_{2}$ dumbbells. The $\mathrm{Tl}_{12}$ units are present in terms of tetrahedral stars, which are well-known characteristics of electron poor intermetallics (VEC 2.1-2.6) [36]. These tetrahedral stars are condensed by forming two-dimensional layers, which are interconnected by the $\mathrm{Tl}_{2}$ dumbbells. The result is a three-dimensional network of thallium atoms with Tl-Tl distances between 3.190(2) Å and 3.711(4). . This is a rather rare arrangement for alkali metal thallides, as with $\mathrm{K}_{49} \mathrm{Tl}_{108}[37,38]$ and $\mathrm{Rb}_{17} \mathrm{Tl}_{41}[39]$ only two other examples for three-dimensional $\mathrm{Tl}$ substructures are known. The remaining thallide structures are lower in $\mathrm{Tl}-\mathrm{Tl}$ dimensionality. The alkali metals in $\mathrm{K}_{6} \mathrm{Tl}_{17}$ are located on five different crystallographic sites. The number of contacts to thallium and potassium atoms within a given distance is given in Table 1 . The altogether number of neighboring atoms within the given distances calculates from 14 to 17 . $\mathrm{K} 3$ represents the most densely coordinated alkali metal in $\mathrm{K}_{6} \mathrm{Tl}_{17}$. In Figure 2, the surroundings of the symmetry inequivalent potassium atoms are given.

By having a closer look at the complete unit cell of the crystal structure (Figure 2), the special surrounding of $\mathrm{K} 3$ is reflected in its position within the two-dimensional layers of tetrahedral stars (bright red), whereas the remaining potassium atoms are situated between these layers (dark red).

Table 1. Surrounding atoms of the symmetry inequivalent potassium positions in $\mathrm{K}_{6} \mathrm{Tl}_{17}$ (space group (ccm).

\begin{tabular}{cccc}
\hline $\begin{array}{c}\text { Symmetry Inequivalent } \\
\text { Alkali Metal }\end{array}$ & Wyckoff Letter & $\begin{array}{c}\text { Number of T1 Neighbors } \\
\text { (Distances Below) }\end{array}$ & $\begin{array}{c}\text { Number of K Neighbors } \\
\text { (Distances Below) }\end{array}$ \\
\hline K1 & $8 l$ & $10(<4.0 \AA)$ & $4(<4.6 \AA)$ \\
K2 & $8 l$ & $9(<4.3 \AA)$ & $6(<4.7 \AA)$ \\
K3 & $8 l$ & $14(<4.3 \AA)$ & $3(<4.4 \AA)$ \\
K4 & $16 m$ & $11(<4.8 \AA)$ & $5(<4.7 \AA)$ \\
K5 & $8 g$ & $11(<4.8 \AA)$ & $4(<4.3 \AA)$ \\
\hline
\end{tabular}




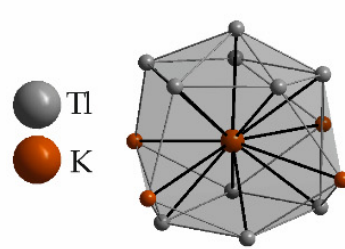

K1

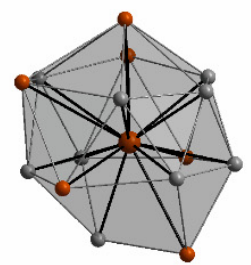

K2

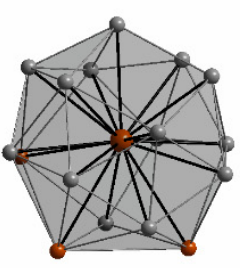

K3

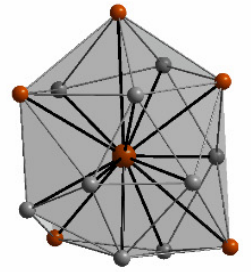

K4

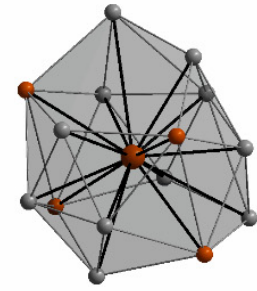

K5

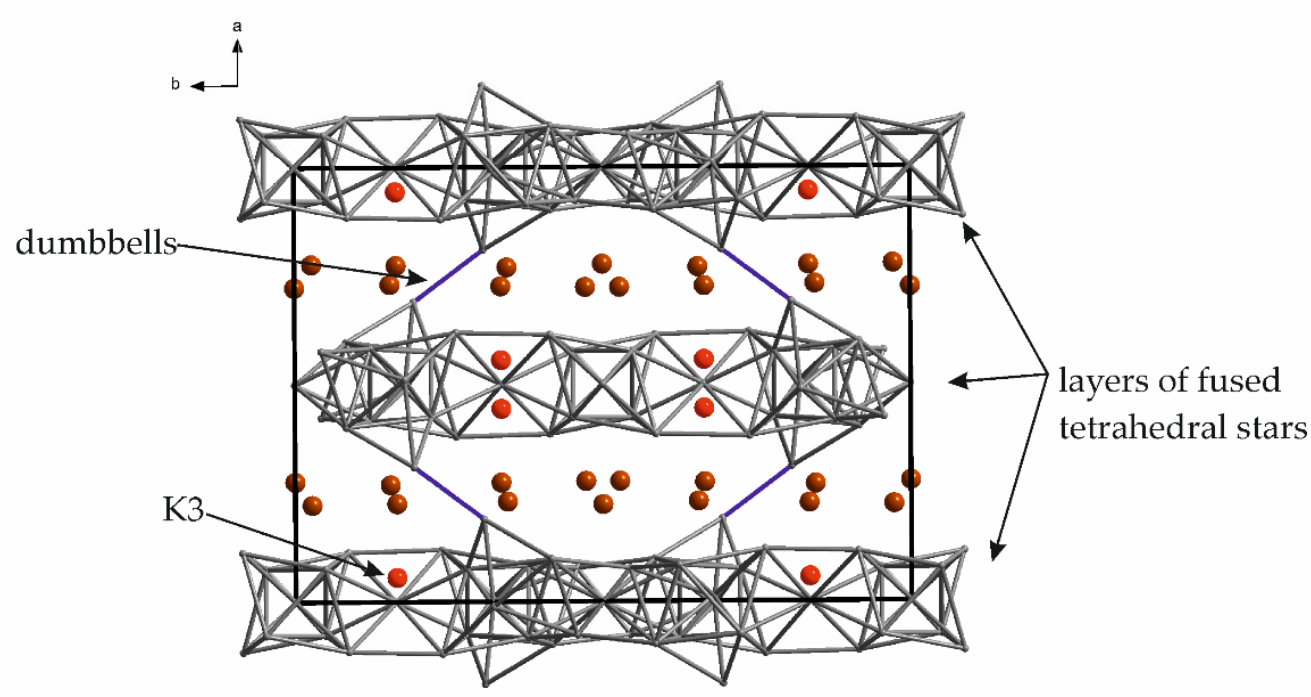

Figure 2. Surroundings of the five crystallographically independent potassium atoms in $\mathrm{K}_{6} \mathrm{Tl}_{17}$. The range of distances as well as the Wyckoff letters for each atom are given in Table 1 . In the unit cell, the $\mathrm{K} 3$ atoms are located within the layers of fused tetrahedral stars (dark red), while the remaining potassium atoms are situated between these layers (bright red).

\section{Atomic Ratio $\mathrm{M}^{\mathrm{I}}: \mathrm{Tl}$ Approximately 1:2}

By increasing the alkali metal content to an extent of approximately half of the thallium amount, three different structure types have been reported.

\section{1. $R b_{17} T l_{41}$ and $K_{49} T l_{108}$}

The structures of the complex cubic compounds $\mathrm{K}_{49} \mathrm{Tl}_{108}[37,38]$ and $\mathrm{Rb}_{17} \mathrm{Tl}_{41}$ [39] can be related to $\beta$-rhombohedral boron $[40,41]$. Here, $\mathrm{Tl}_{84}$ units are the main structural entities, which consist of a central $\mathrm{Tl}_{12}$ icosahedron. This icosahedron again is coordinated icosahedrally by $12 \mathrm{Tl}$ atoms, which are interconnected by $\mathrm{Tl}$ atoms under the formation of pentagonal pyramids. Figure 3 shows the unit cell of $\mathrm{K}_{49} \mathrm{Tl}_{108}$ (by only taking shorter $\mathrm{Tl}-\mathrm{Tl}$ distances into account), where the empty $\mathrm{Tl}_{12}$ icosahedra are given in red. The remaining $\mathrm{Tl}$ atoms form chains of Tl-centered pentagonal antiprisms, which are interconnected by two $\mathrm{Tl}$ atoms. The complex arrangement of a Samson polyhedron (12 pentagonal and 20 hexagonal faces) is known for $\mathrm{B}_{84}$ clusters in $\beta$-rhombohedral boron. The $\mathrm{Tl}_{84}$ entities are connected via common hexagonal faces to form a three-dimensional network of $\mathrm{Tl}$ atoms. In $\mathrm{K}_{49} \mathrm{Tl}_{108}$ six symmetry inequivalent positions of potassium are present (Table 2). The first coordination spheres of potassium by only taking $\mathrm{Tl}$ atoms into account, are built by 12 atoms (capped tetrahedra, $\mathrm{K} 2$, K4, K5), 8 atoms (hexagonal antiprism, K3), 11 atoms (K1), and 14 atoms (capped hexagonal prism, K6). By also taking distances of slightly higher values into account, an extended atomic environment can be described. This results in 15 to 20 neighboring atoms (15: K1, K3; 16: K2, K4, K5; 20: K6). The careful comparison of the surroundings reveals the major discrepancy between $\mathrm{K} 5$ and $\mathrm{K} 6$. $\mathrm{K} 5$ has 16 adjacent 
atoms at short distances below $4 \AA$, which results in a small interior void. In contrast, 20 atoms at mostly larger distances provide more space for K6 (Figure 3).

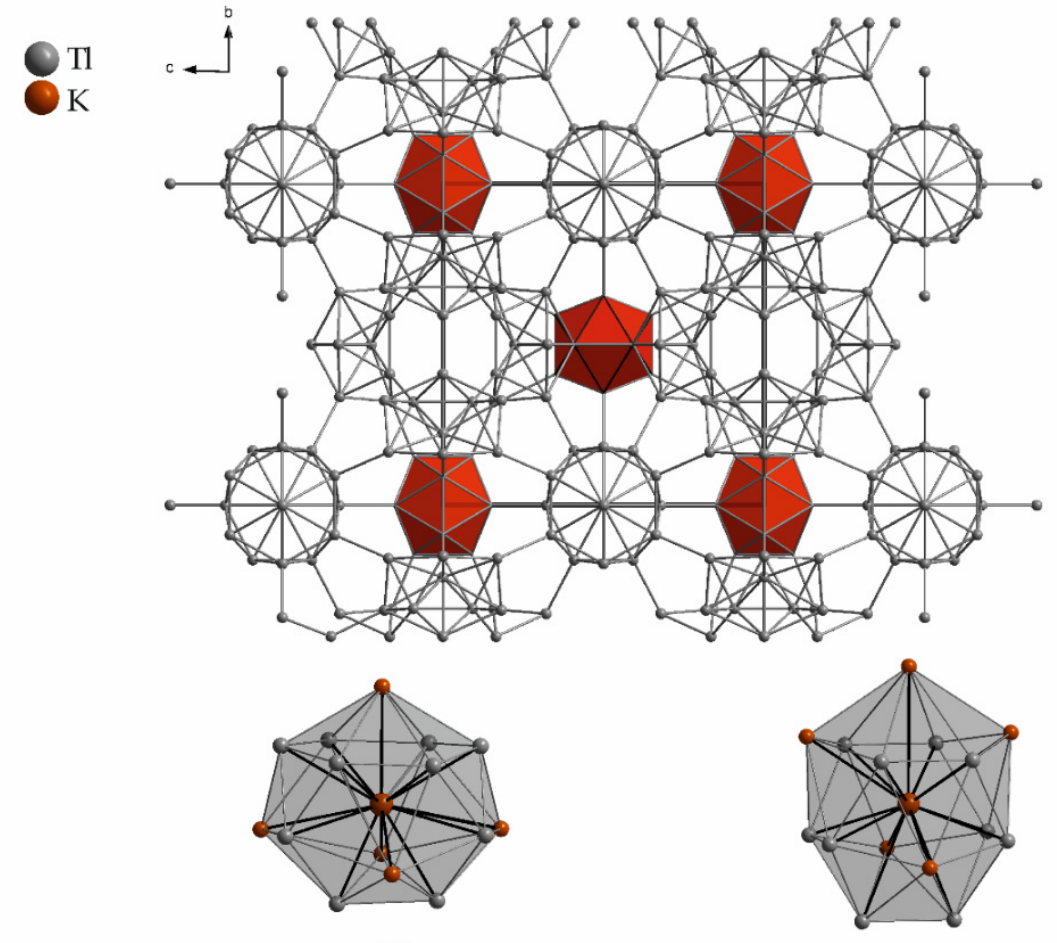

K1

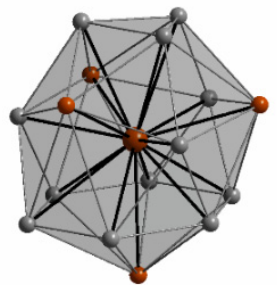

K2

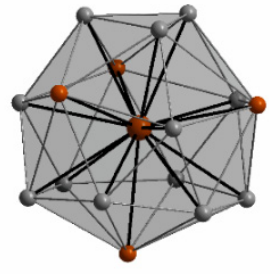

K4

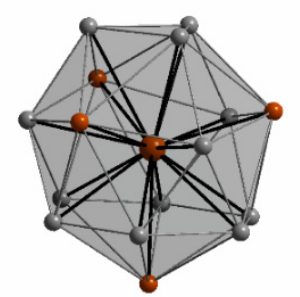

K5
K3

Figure 3. Unit cell and surroundings of the six symmetry inequivalent potassium positions in $\mathrm{K}_{49} \mathrm{Tl}_{108}$. The corresponding range of distances to the adjacent atoms as well as the Wyckoff letters are given in Table 2.

Table 2. Surrounding atoms of the symmetry inequivalent potassium positions in $\mathrm{K}_{49} \mathrm{Tl}_{108}$ (space group Pm-3).

\begin{tabular}{cccc}
\hline $\begin{array}{c}\text { Symmetry Independent } \\
\text { Alkali Metal }\end{array}$ & Wyckoff Letter & $\begin{array}{c}\text { Number of T1 Neighbors } \\
\text { (Distances Below) }\end{array}$ & $\begin{array}{c}\text { Number of K Neighbors } \\
\text { (Distances Below) }\end{array}$ \\
\hline K1 & $12 k$ & $10(<4.2 \AA)$ & $4(<4.3 \AA)$ \\
K2 & $12 j$ & $12(<4.4 \AA)$ & $4(<4.3 \AA)$ \\
K3 & $6 g$ & $10(<4.4 \AA)$ & $4(<4.3 \AA)$ \\
K4 & $8 i$ & $12(<4.2 \AA)$ & $+1(<4.7 \AA)$ \\
K5 & $8 i$ & $12(<4.0 \AA)$ & $4(<4.0 \AA)$ \\
K6 & $3 c$ & $14(<4.4 \AA)$ & $4(<4.0 \AA)$ \\
& & & $4(<4.3 \AA)$ \\
& & & $+2(<4.7 \AA)$ \\
\hline
\end{tabular}

The compound $\mathrm{Rb}_{17} \mathrm{Tl}_{41}$ [39] (VEC 2.41) ( $\mathrm{K}_{17} \mathrm{In}_{41}$ type structure [42]) is even higher in symmetry (space group $F d-3 m$ ) and only three symmetry inequivalent rubidium atoms are present (Table 3), 
which due to their site symmetry $(96 g, 32 e, 8 a)$ all are located in the center of a capped tetrahedron built by 12 coordinating thallium atoms at distances up to $4.2 \AA$. The surrounding is completed by four rubidium atoms at distances up to $4.3 \AA$, which gives 16 neighboring atoms for each rubidium in $\mathrm{Rb}_{17} \mathrm{Tl}_{41}$ (Figure 4). The thallium substructure again can be described by linked Samson polyhedra. In Figure 4 the unit cell is given, showing the three-dimensional connection of empty $\mathrm{Tl}_{12}$ icosahedra (only shorter $\mathrm{Tl}-\mathrm{Tl}$ distances are taken into account). The rubidium atoms themselves form pentagonal dodecahedra, which are connected via their pentagonal faces to form a three-dimensional network analogous to the clathrate-II structure [43-45].

Table 3. Surrounding atoms of the symmetry inequivalent potassium positions in $\mathrm{Rb}_{17} \mathrm{Tl}_{41}$ (space group Fd-3m).

\begin{tabular}{cccc}
\hline $\begin{array}{c}\text { Symmetry Independent } \\
\text { Alkali Metal }\end{array}$ & Wyckoff Letter & $\begin{array}{c}\text { Number of T1 Neighbors } \\
\text { (Distances Below) }\end{array}$ & $\begin{array}{c}\text { Number of Rb Neighbors } \\
\text { (Distances Below) }\end{array}$ \\
\hline $\mathrm{Rb} 1$ & $96 g$ & $12(<4.2 \AA)$ & $4(<4.3 \AA)$ \\
$\mathrm{Rb} 2$ & $32 e$ & $12(<4.0 \AA)$ & $4(<4.3 \AA)$ \\
$\mathrm{Rb} 3$ & $8 a$ & $12(<4.0 \AA)$ & $4(<4.3 \AA)$ \\
\hline
\end{tabular}

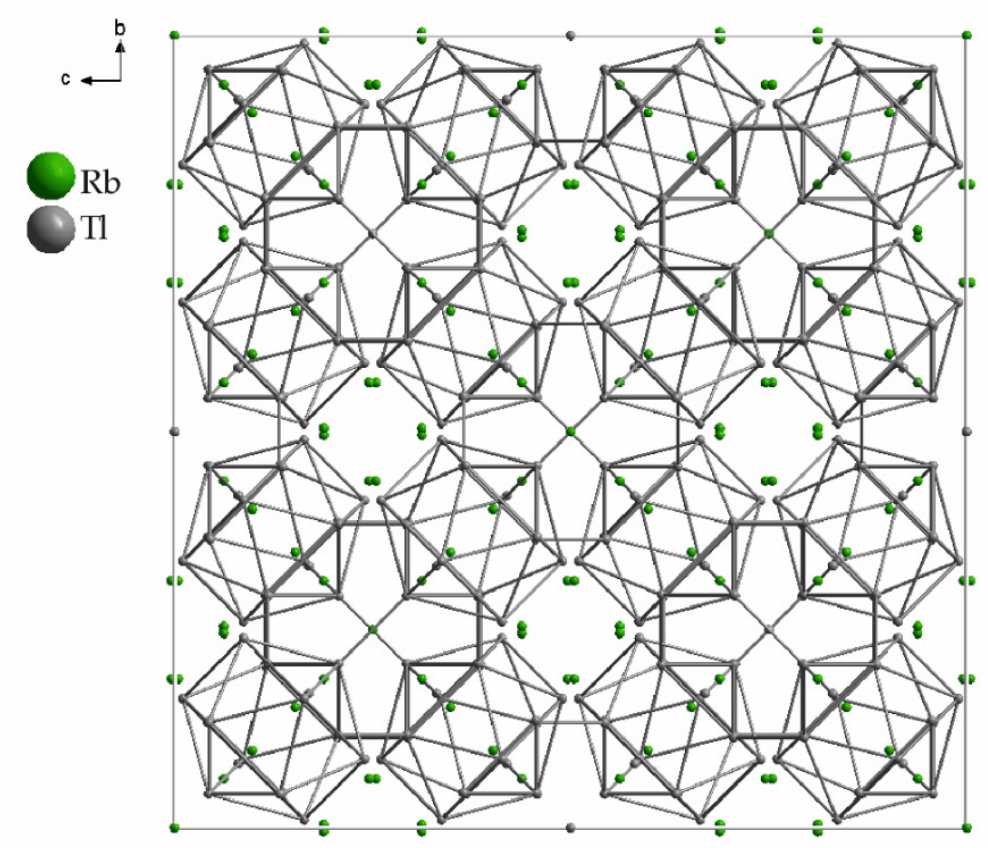

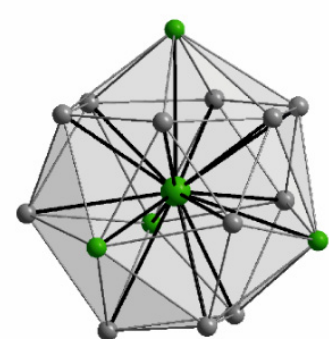

Rb1

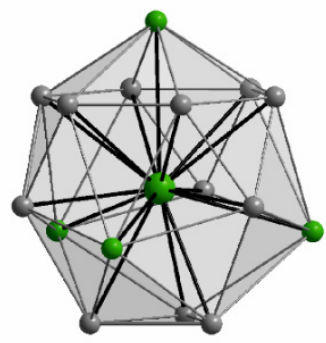

$\mathrm{Rb} 2$

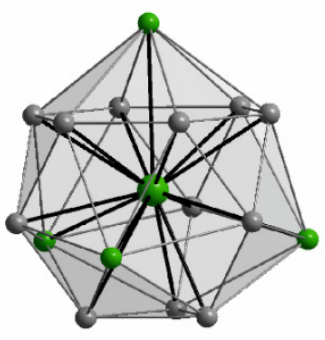

$\mathrm{Rb3}$

Figure 4. Unit cell and surroundings of the three symmetry inequivalent potassium positions in $\mathrm{Rb}_{17} \mathrm{Tl}_{41}$. The corresponding range of distances to the adjacent atoms as well as the Wyckoff letters are given in Table 3. 


\section{2. $A_{15} T l_{27}(A=R b, C s)$}

The VEC of $\sim 2.33$ again falls within the range of the tetrahedral star regime (see Section 2, $\left.\mathrm{K}_{6} \mathrm{Tl}_{17}\right)$, and indeed for $\mathrm{A}_{15} \mathrm{Tl}_{27}(\mathrm{~A}=\mathrm{Rb}, \mathrm{Cs})$ [35] the structural motif of double tetrahedral stars (DTS) is observed. Figure 4 shows parts of the crystal structure of $\mathrm{Rb}_{15} \mathrm{Tl}_{27}$ as representative for the $\mathrm{A}_{15} \mathrm{Tl}_{27}$ structure family. This compound includes two different DTS units. Figure $5 \mathrm{a}$ shows the DTS arrangement, which is further condensed by forming $\left(\mathrm{Tl}_{6 / 2} \mathrm{Tl}_{3 / 1} \mathrm{Tl}_{2 / 1}\right)_{2}\left(\equiv \mathrm{Tl}_{16}\right)$ layers (green in Figure $5 \mathrm{c}, \mathrm{d}$ ). The second distorted DTS unit is represented by isolated $\mathrm{Tl}_{11}{ }^{7-}$ clusters (point group $D_{3 h}$, Figure $5 \mathrm{a}$ ), which are located below and above the large pores of the layers (blue, Figure $5 \mathrm{c}, \mathrm{d}$ ).

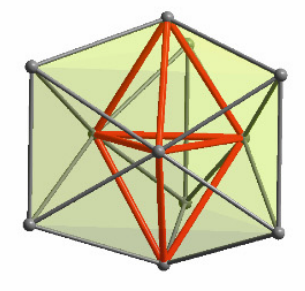

a

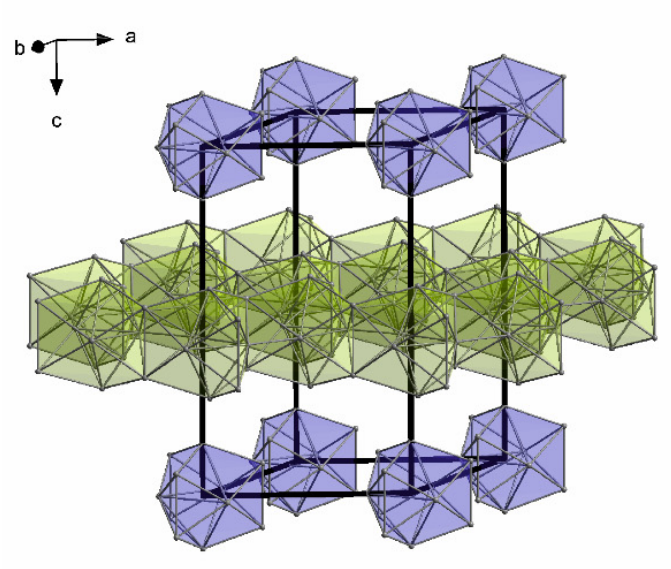

C

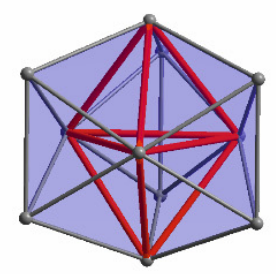

$\mathrm{b}$

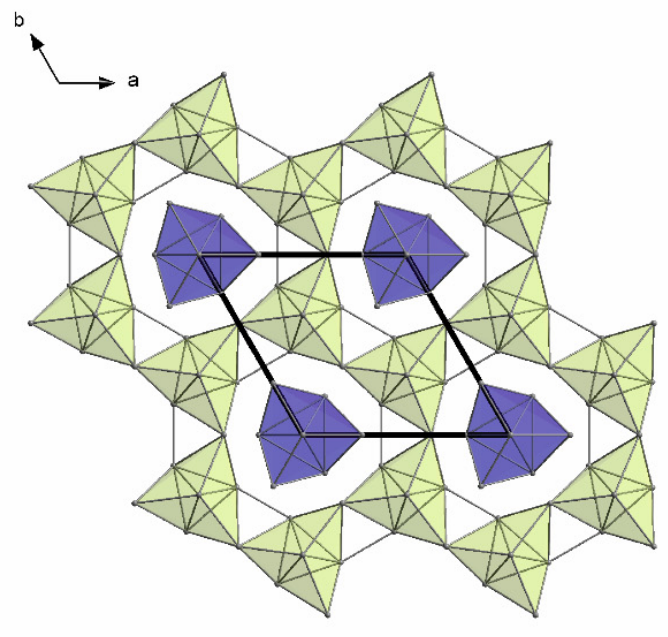

d

Figure 5. Thallium substructures in $\mathrm{Rb}_{15} \mathrm{Tl}_{27}$ : (a) $\mathrm{Tl}_{11}$ subunits (double tetrahedral stars) which build the Tl layer; (b) isolated $\mathrm{Tl}_{11}{ }^{7-}$ clusters (double tetrahedral stars); (c,d) isolated $\mathrm{Tl}_{11}{ }^{7-}$ clusters and layers formed by the condensation of $\mathrm{Tl}_{11}$ subunits in the unit cell of $\mathrm{Rb}_{15} \mathrm{Tl}_{27}$.

Due to the high symmetry of the space group $P-62 m$, only four crystallographically independent alkali metal sites are present in $\mathrm{A}_{15} \mathrm{Tl}_{27}$ type structures. In Table 4, the number and the range of distances of the four symmetry independent alkali metal positions in $\mathrm{Rb}_{15} \mathrm{Tl}_{27}$, as the representative for all $\mathrm{A}_{15} \mathrm{Tl}_{27}$ compounds, to the neighboring atoms are given. The number of surrounding atoms for each rubidium ranges from 13 to 18 . Thereby, two sets of alkali metals emerge: Rb1 and Rb3 show less contacts (Rb1: 13, Rb3: 14) within a larger range of distances between 4 and $4.9 \AA$. In contrast, Rb2 and $\mathrm{Rb} 4$ exhibit larger distances to a higher number of neighboring atoms ( $\mathrm{Rb} 2: 15, \mathrm{Rb} 4: 18)$. In particular, the position of $\mathrm{Rb} 4$ is conspicuous due to an outstanding high number of adjacent atoms. Figure 6 shows the unit cell of $\mathrm{Rb}_{15} \mathrm{Tl}_{27}$, where the two sets of alkali metal positions are also reflected. The first set occupies positions within the $\mathrm{Tl}$ layers ( $\mathrm{Rb} 4$, blue) and connects the $\mathrm{Tl}_{11}$ clusters ( $\mathrm{Rb} 2$, yellow). The second set ( $\mathrm{Rb} 1$ (red) and $\mathrm{Rb} 3$ (green)) is located in between the layers of the thallium substructures. 
Table 4. Surrounding atoms of the symmetry inequivalent potassium positions in $\mathrm{Rb}_{15} \mathrm{Tl}_{27}$ (space group $P-62 m$ ).

\begin{tabular}{cccc}
\hline $\begin{array}{c}\text { Symmetry Independent } \\
\text { Alkali Metal }\end{array}$ & Wyckoff Letter & $\begin{array}{c}\text { Number of T1 Neighbors } \\
\text { (Distances Below) }\end{array}$ & $\begin{array}{c}\text { Number of Rb Neighbors } \\
\text { (Distances Below) }\end{array}$ \\
\hline $\mathrm{Rb} 1$ & $6 i$ & $5(<4.0 \AA)$ & $3(<4.4 \AA)$ \\
$\mathrm{Rb} 2$ & $2 c$ & $+3(<4.4 \AA)$ & $+2(<4.6 \AA)$ \\
$\mathrm{Rb} 3$ & $6 i$ & $9(<4.4 \AA)$ & $6(<4.6 \AA)$ \\
$\mathrm{Rb} 4$ & $1 b$ & $9(<4.0 \AA)$ & $4(<4.4)$ \\
& $12(<4.4 \AA)$ & $6(1<4.9 \AA)$ \\
\hline
\end{tabular}

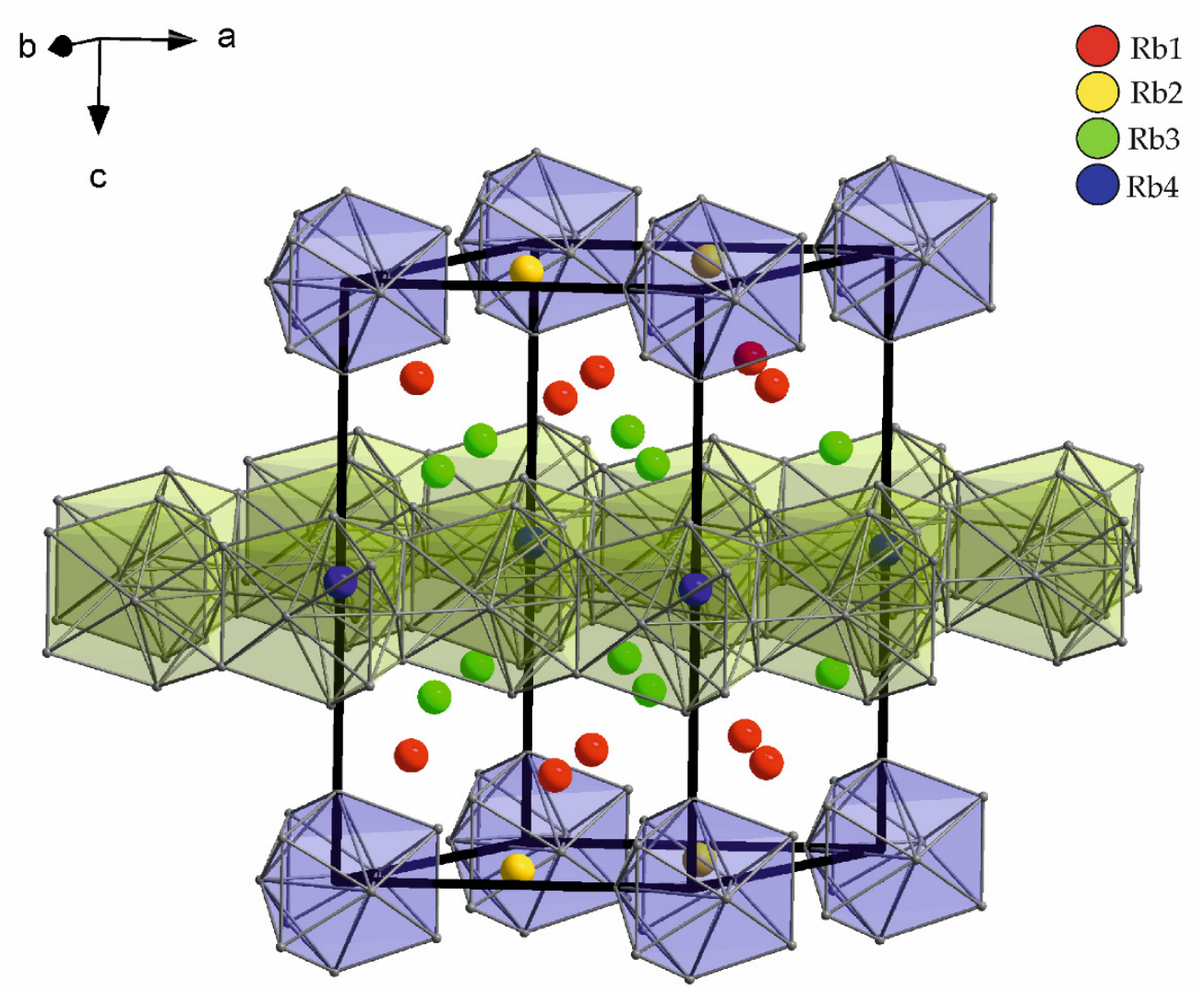

Figure 6. Four symmetry inequivalent $\mathrm{Rb}$ positions in $\mathrm{Rb}_{15} \mathrm{Tl}_{27}$. $\mathrm{Rb} 2$ connects the $\mathrm{Tl}_{11}{ }^{7-}$ clusters, $\mathrm{Rb} 4$ is situated within the $\mathrm{Tl}$ layers formed by condensed $\mathrm{Tl}_{11}$ subunits. $\mathrm{Rb} 1$ and $\mathrm{Rb} 3$ are located between the two different $\mathrm{Tl}$ substructures.

The possibility of an ordered substitution of $\mathrm{Rb} 4$ by the largest alkali metal cesium was shown for the compound $\mathrm{Rb}_{14} \mathrm{CsTl}_{27}$ [35].

Despite the very similar VEC of $\mathrm{K}_{49} \mathrm{Tl}_{108}$ (VEC 2.38) and $\mathrm{A}_{15} \mathrm{Tl}_{27}$ (VEC 2.29), both structure types have not yet been reported vice versa concerning the type of alkali metal.

\section{Atomic Ratio $\mathrm{M}^{\mathrm{I}}: \mathrm{Tl}$ Approximately 3:4}

A further increase of the alkali metal amount results in lower VEC and higher VEC Zintl, respectively. This means a reduction of the number of $\mathrm{Tl}-\mathrm{Tl}$ contacts, which lowers the dimensionality of the $\mathrm{Tl}$ sublattice and results in the formation of isolated clusters. 


\section{1. $A_{8} T_{11}(A=K, R b, C s)$}

$\mathrm{A}_{8} \mathrm{Tl}_{11}$ binary phases $(\mathrm{A}=\mathrm{K}, \mathrm{Rb}, \mathrm{Cs})[46,47]$ crystallize in the $\mathrm{K}_{8} \mathrm{In}_{11}$ type structure (space group $R$-3c) [48]. The anionic moiety is represented by a $\mathrm{Tl}_{11}$ cluster, but in contrast to their highest possible symmetry ( $D_{3 h}$ in $A_{15} T_{27}$; see Section 3.2), here only $D_{3}$ symmetry for the $\mathrm{Tl}_{11}$ unit is realized, according to their site symmetry. The substitution of the extra electron in $\mathrm{A}_{8} \mathrm{Tl}_{11}$ by halide results in $\mathrm{A}_{8} \mathrm{Tl}_{11} \mathrm{X}$, in which a less degree of distortion of the $\mathrm{Tl}_{11}{ }^{7-}$ cluster is observed, electronic effects of the extra electron therefore cannot be excluded [49]. Due to the high symmetry of the crystal structure, only two symmetry inequivalent alkali metal sites are present in $\mathrm{A}_{8} \mathrm{Tl}_{11}$. In Table 5, the number of contacts and the corresponding distances to thallium as well as rubidium in $\mathrm{Rb}_{8} \mathrm{Tl}_{11}$ as representative for all $\mathrm{A}_{8} \mathrm{Tl}_{11}$ structures are given. While $\mathrm{Rb} 2$ shows contacts to altogether 15 atoms within $4.6 \AA$, Rb1 exhibits only 12 surrounding atoms (Figure 7). This makes the position of Rb1 conspicuous and indeed, having a closer look at the crystal structure, this position is involved in the formation of a distorted octahedral arrangement around a void. This void can be filled by halide yielding an enlarged number of surrounding atoms of $\mathrm{Rb} 1$ of 13 [49]. In general, for binary $\mathrm{A}_{8} \mathrm{Tl}_{11}$ no site occupancy preferences for different alkali metals have been reported.

Table 5. Surrounding atoms of the symmetry inequivalent rubidium positions in $\mathrm{Rb}_{8} \mathrm{Tl}_{11}$ (space group $R-3 c$ ).

\begin{tabular}{cccc}
\hline $\begin{array}{c}\text { Symmetry Independent } \\
\text { Alkali Metal }\end{array}$ & Wyckoff Letter & $\begin{array}{c}\text { Number of T1 Neighbors } \\
\text { (Distances Below) }\end{array}$ & $\begin{array}{c}\text { Number of Rb Neighbors } \\
\text { (Distances Below) }\end{array}$ \\
\hline $\mathrm{Rb} 1$ & $36 f$ & $7(<4.3 \AA)$ & $5(<4.6 \AA)$ \\
$\mathrm{Rb} 2$ & $12 c$ & $9(<4.3 \AA)$ & $6(<4.6 \AA)$ \\
\hline
\end{tabular}

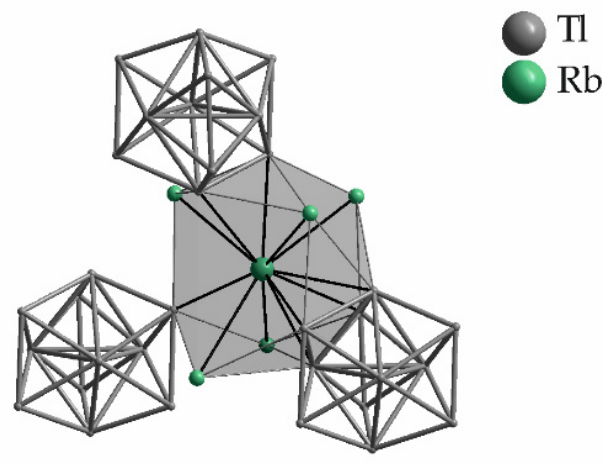

$\mathrm{Rb} 1$

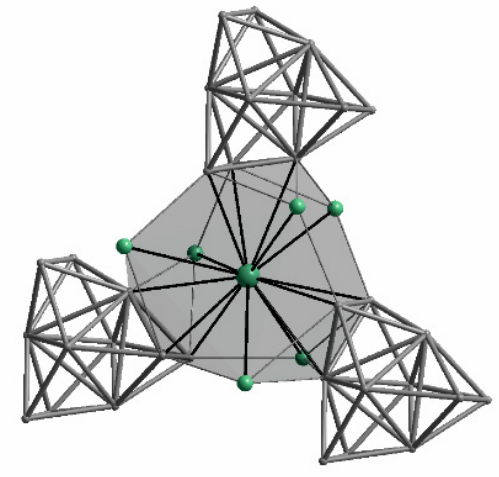

$\mathrm{Rb} 2$

Figure 7. Surroundings of the two symmetry inequivalent rubidium positions in $\mathrm{Rb}_{8} \mathrm{Tl}_{11}$. The corresponding range of distances to the adjacent atoms as well as the Wyckoff letters are given in Table 5.

\section{2. $N a_{4} A_{6} T l_{13}(A=K, R b, C s)$ and $N a_{3} K_{8} T l_{13}$}

In 1994, Corbett et al. demonstrated on the basis of the compound $\mathrm{Na}_{2} \mathrm{~K}_{21} \mathrm{Tl}_{19}$ [50] (see Section 5.3) that the involvement of different alkali metals within one thallide compound had a significant influence on the formed crystal structure. They also introduced this concept at a ratio of 3:4 of $\mathrm{M}^{\mathrm{I}}: \mathrm{Tl}$ and subsequently reported on $\mathrm{Na}_{4} \mathrm{~A}_{6} \mathrm{Tl}_{13}(\mathrm{~A}=\mathrm{K}, \mathrm{Rb}, \mathrm{Cs})$ and $\mathrm{Na}_{3} \mathrm{~K}_{8} \mathrm{Tl}_{13}$ [51]. According to the $\mathrm{A}_{8} \mathrm{Tl}_{11}$ compounds, we would expect isolated clusters in this area of the VEC. In fact, centered, icosahedral shaped $\mathrm{Tl}_{13}$ clusters are found when sodium and additionally a heavier congener are mixed. The shape of the open-shell $\mathrm{Tl}_{13}{ }^{10-}$ clusters in $\mathrm{Na}_{4} \mathrm{~A}_{6} \mathrm{Tl}_{13}$ is not significantly changed for closed shell $\mathrm{Tl}_{13}{ }^{11-}$ in $\mathrm{Na}_{3} \mathrm{~K}_{8} \mathrm{Tl}_{13}$, but the overall structure changes from former bcc (body-centred cubic) packing of $\mathrm{Tl}_{13}{ }^{10-}$ clusters in $\mathrm{Na}_{4} \mathrm{~A}_{6} \mathrm{Tl}_{13}$ into pseudo fcc (face-centred cubic) packing of formal $\mathrm{Tl}_{13}{ }^{11-}$ in $\mathrm{Na}_{3} \mathrm{~K}_{8} \mathrm{Tl}_{13}$. 
The number of sodium atoms of the first coordination sphere of the clusters is reduced from eight in $\mathrm{Na}_{4} \mathrm{~K}_{6} \mathrm{Tl}_{13}$ to six in $\mathrm{Na}_{3} \mathrm{~K}_{8} \mathrm{Tl}_{13}$. A loss of electronic reasons for the formation of open shell $\mathrm{Tl}_{13}{ }^{10-}$ emphasizes the dominant effects of packing requirements [47]. The presence of sodium is essential for the formation of these compounds. All attempts to prepare a compound including $\mathrm{Tl}_{13}{ }^{10 / 11-}$ in absence of sodium have not yet succeeded. In addition, the replacement of potassium by larger alkali metals rubidium or cesium did not result in $\mathrm{Na}_{3} \mathrm{~A}_{8} \mathrm{Tl}_{13}$ but always in $\mathrm{Na}_{4} \mathrm{~A}_{6} \mathrm{Tl}_{13}$. Significant differences between $\mathrm{Na}_{4} \mathrm{~K}_{6} \mathrm{Tl}_{13}$ and $\mathrm{Na}_{3} \mathrm{~K}_{8} \mathrm{Tl}_{13}$ become apparent, when comparing the adjacent atoms and the corresponding distances of the alkali metals (Tables 6 and 7). The distorted icosahedral coordination of the sodium cations by $6 \mathrm{Tl}$ atoms and 6 potassium neighbors virtually is the same in both compounds (Figure 8). The value for the Na1-K1 distance of 4.168(2) $\AA$ in $\mathrm{Na}_{4} \mathrm{~K}_{6} \mathrm{Tl}_{13}$ is longer than both $\mathrm{Na}-\mathrm{K}$ distances found in $\mathrm{Na}_{3} \mathrm{~K}_{8} \mathrm{Tl}_{13}(\mathrm{~d}(\mathrm{Na} 1-\mathrm{K} 1=3.638(6) \AA$; $\mathrm{d}(\mathrm{Na} 1-\mathrm{K} 2)=4.076(6) \AA)$.

In contrast to the similarity of the sodium environment, the surroundings of the potassium atoms are significantly different (Figure 8). In $\mathrm{Na}_{4} \mathrm{~K}_{6} \mathrm{Tl}_{13}$, potassium is surrounded at comparably short distances up to $4 \AA$. In $\mathrm{Na}_{3} \mathrm{~K}_{8} \mathrm{Tl}_{13}$, the case is different. The potassium environment is built by 12 (for K1) and 11 (for K2) atoms at shorter distances below $4.1 \AA$, whereas additional 3 (for K1) and 5 (for K2) atoms at larger distances up to $4.8 \AA$ complete the altogether surrounding of 15 (for K1) and 16 (for K2) atoms, respectively. This is according to a more cylindrical shaped space for K1 and K2, respectively, compared to the rather spherical surrounding of $\mathrm{K} 1$ in $\mathrm{Na}_{4} \mathrm{~K}_{6} \mathrm{Tl}_{13}$ (Figure 8).

Corbett et al. suggested that, in this kind of material, the holes in which sodium is located are too small for the larger alkali metals; therefore, this structure type can only be realized in the presence of small sodium. In general, the different sized cavities in compounds including icosahedral clusters need to be filled by the suitable alkali metal resulting in an effective packing mode. By virtue of the large K-K distances observed for $\mathrm{Na}_{3} \mathrm{~K}_{8} \mathrm{Tl}_{13}$, the nonexistence of $\mathrm{Na}_{3} \mathrm{Rb}_{8} \mathrm{Tl}_{13}$ and $\mathrm{Na}_{3} \mathrm{Cs}_{8} \mathrm{Tl}_{13}$ might additionally be explained by too large $\mathrm{Rb}-\mathrm{Rb}$ and $\mathrm{Cs}-\mathrm{Cs}$ distances for an effective packing.

Table 6. Surrounding atoms of the symmetry inequivalent rubidium positions in $\mathrm{Na}_{4} \mathrm{~K}_{6} \mathrm{Tl}_{13}$ (space group Im-3).

\begin{tabular}{ccccc}
\hline $\begin{array}{c}\text { Symmetry } \\
\text { Independent } \\
\text { Alkali Metal }\end{array}$ & $\begin{array}{c}\text { Wyckoff } \\
\text { Letter }\end{array}$ & $\begin{array}{c}\text { Number of T1 } \\
\text { Neighbors } \\
\text { (Distances Below) }\end{array}$ & $\begin{array}{c}\text { Number of K } \\
\text { Neighbors } \\
\text { (Distances Below) }\end{array}$ & $\begin{array}{c}\text { Number of Na } \\
\text { Neighbors } \\
\text { (Distances Below) }\end{array}$ \\
\hline $\mathrm{K} 1$ & $6 f$ & $8(<3.6 \AA)$ & $5(<4.0 \AA)$ & $4(<4.0 \AA)$ \\
$\mathrm{Na} 1$ & $8 i$ & $6(<3.2 \AA)$ & $6(<4.2 \AA)$ & - \\
\hline
\end{tabular}

Table 7. Surrounding atoms of the symmetry inequivalent rubidium positions in $\mathrm{Na}_{3} \mathrm{~K}_{8} \mathrm{Tl}_{13}$ (space group $R-3 m$ ). The color-coding refers to the color of the contacts in Figure 8.

\begin{tabular}{ccccc}
\hline $\begin{array}{c}\text { Symmetry } \\
\text { Independent } \\
\text { Alkali Metal }\end{array}$ & $\begin{array}{c}\text { Wyckoff } \\
\text { Letter }\end{array}$ & $\begin{array}{c}\text { Number of T1 } \\
\text { Neighbors } \\
\text { (Distances Below) }\end{array}$ & $\begin{array}{c}\text { Number of K } \\
\text { Neighbors } \\
\text { (Distances Below) }\end{array}$ & $\begin{array}{c}\text { Number of Na } \\
\text { Neighbors } \\
\text { (Distances Below) }\end{array}$ \\
\hline K1 & $6 c$ & $6(<3.9 \AA)$ & $\begin{array}{c}3(<4.1 \AA) \\
+3(<4.8 \AA)\end{array}$ & $3(<4.1 \AA)$ \\
K2 & $18 h$ & $7(<3.9 \AA)$ & $\begin{array}{c}2(<4.1 \AA) \\
+5(<4.8 \AA)\end{array}$ & $2(<4.1 \AA)$ \\
$\mathrm{Na} 1$ & $9 d$ & $6(<3.9 \AA)$ & $6(<4.1 \AA)$ & - \\
\hline
\end{tabular}



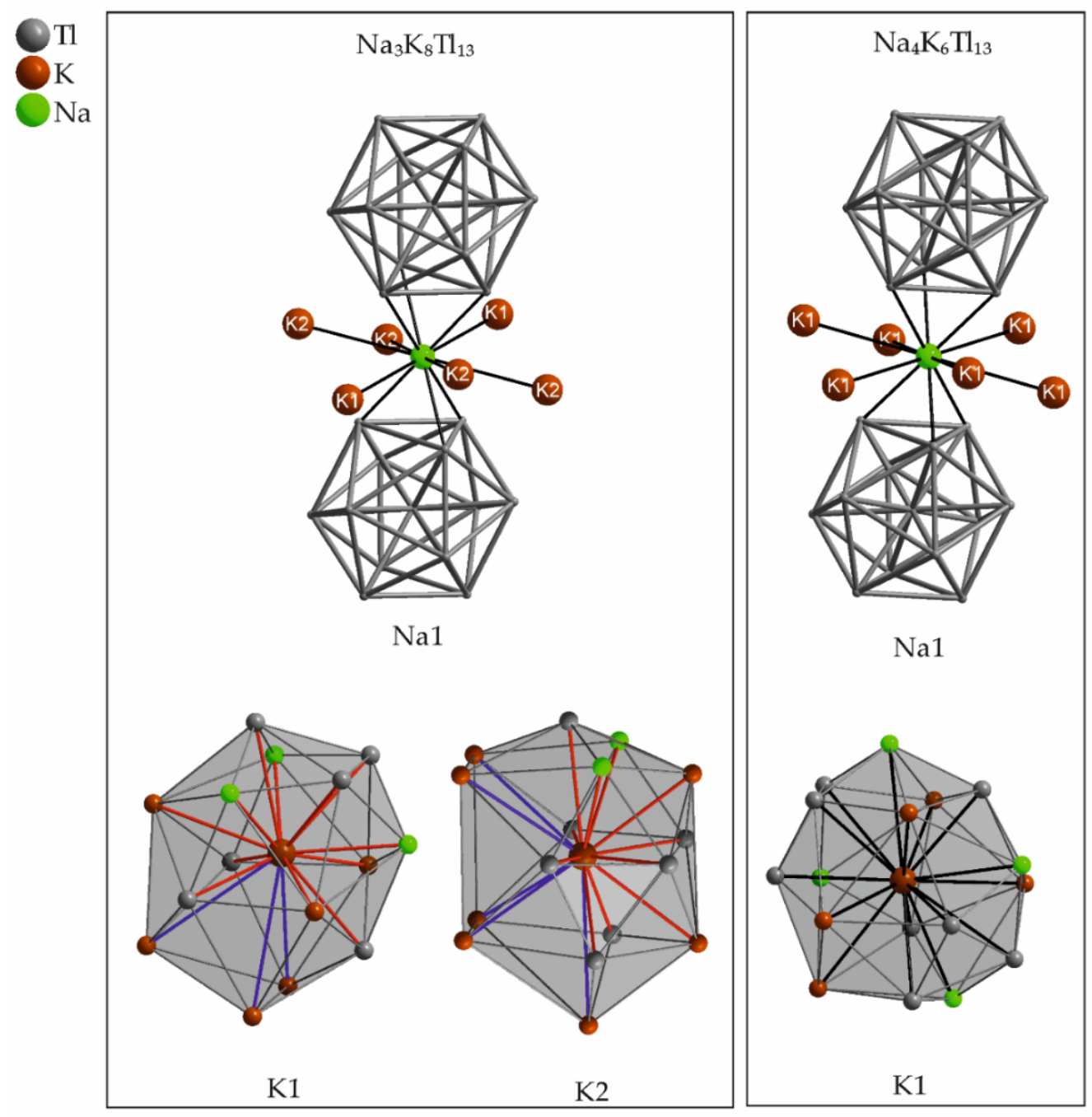

Figure 8. Atomic environment of the symmetry inequivalent sodium and potassium position(s) in $\mathrm{Na}_{3} \mathrm{~K}_{8} \mathrm{Tl}_{13}$ and $\mathrm{Na}_{4} \mathrm{~K}_{6} \mathrm{Tl}_{13}$. The corresponding range of distances to the adjacent atoms as well as the Wyckoff letters are given in Table $6\left(\mathrm{Na}_{4} \mathrm{~K}_{6} \mathrm{Tl}_{13}\right)$ and Table $7\left(\mathrm{Na}_{3} \mathrm{~K}_{8} \mathrm{Tl}_{13}\right)$.

\section{Atomic Ratio $\mathbf{M}^{\mathrm{I}}: \mathrm{Tl}$ Approximately 1:1}

\section{1. $\operatorname{ATl}(A=L i, N a, K, C s)$}

In the area of similar stoichiometric amounts of alkali metal and thallium, formally one negative charge per thallium atom is present. According to the Zintl-Klemm formalism, this means a fourfold bound $\mathrm{Tl}$ atom, which in $\mathrm{NaTl}[1,52-55]$ is realized by the formation of a diamond like sublattice in terms of a three-dimensional network of tetrahedrally coordinated thallium. LiTl crystallizes in the $\beta$-brass type structure [56]. In KTl [57] (ambient conditions) and CsTl [58], octahedral $\mathrm{Tl}_{6}{ }^{6-}$ anions are present, in which also formally fourfold bound $\mathrm{Tl}$ atoms are realized. According to Wade's rules $[59,60]$, one would expect for a closo cluster $(2 n+2)$ skeletal electrons, which is equivalent to an eightfold charge of a Tl cluster consisting of six atoms. The reduced charge of $\mathrm{Tl}_{6}{ }^{6-}$ in $\mathrm{KTl}$ and CsTl, respectively, would result in a hypo-closo cluster with $2 n$ skeletal electrons. This deficiency in electrons accounts for a Jahn Teller distortion with an axial compression, which was supported by extended Hückel calculations for KTl [57]. In general, the hypo-closo clusters are not only stabilized by Jahn Teller distortion, but also relativistic effects, especially spin orbit coupling [16,32]. Comparing KTl and CsTl more in detail, the differences in the shapes of the octahedral anions become apparent. In KTl, the waist of the octahedron is rectangular with two significantly differing distances (3.341 $\AA$ and 
$3.466 \AA)$, the crystallographic point group here is $C_{2 h}(2 / \mathrm{m})$. For $\mathrm{Tl}_{6}{ }^{6-}$ in CsTl these distances are more similar (3.409 $\AA$ and $4.434 \AA$ ) but the rectangular arrangement is slightly tilted, the crystallographic point group is $D_{2}$ with only slight difference from $D_{4 h}$. The reasons for the differences of $\mathrm{Tl}_{6}{ }^{6-}$ in $\mathrm{KTl}^{\mathrm{K}}$ and CsTl are not due to electronic effects but seem to be retrieved in size effects of the cations and their packing requirements [58]. In the following, attention will be drawn at the different local environments of the alkali metal sites in binary 1:1 alkali metal thallides (Table 8 (LiTl), Table 9 (NaTl), Table 10 (KTl), Table 11(CsTl)).

Table 8. Surrounding atoms of the symmetry inequivalent alkali metal position in LiTl (space group $P m-3 m$ ). The color-coding refers to the color of the contacts in Figure 9.

\begin{tabular}{cccc}
\hline $\begin{array}{c}\text { Symmetry Independent } \\
\text { Alkali Metal }\end{array}$ & Wyckoff Letter & $\begin{array}{c}\text { Number of Tl Neighbors } \\
\text { (Distances Below) }\end{array}$ & $\begin{array}{c}\text { Number of Li Neighbors } \\
\text { (Distances Below) }\end{array}$ \\
\hline Li1 & $1 a$ & $8(<3 \AA)$ & $6(<3.5 \AA)$ \\
\hline
\end{tabular}

Table 9. Surrounding atoms of the symmetry inequivalent alkali metal position in NaTl (true for both space groups $F d-3 m$ and $\left.I 4_{1} / a c d\right)$. The color-coding refers to the color of the contacts in Figure 9.

\begin{tabular}{cccc}
\hline $\begin{array}{c}\text { Symmetry Independent } \\
\text { Alkali Metal }\end{array}$ & Wyckoff Letter & $\begin{array}{c}\text { Number of T1 Neighbors } \\
\text { (Distances Below) }\end{array}$ & $\begin{array}{c}\text { Number of Na Neighbors } \\
\text { (Distances Below) }\end{array}$ \\
\hline $\mathrm{Na} 1$ & $\begin{array}{c}8 a(F d-3 m) \\
4 a\left(I 4_{1} / a c d\right)\end{array}$ & $\begin{array}{c}4(<3.3 \AA) \\
+6(<3.8 \AA)\end{array}$ \\
\hline
\end{tabular}

Table 10. Surrounding atoms of the symmetry inequivalent alkali metal positions in KTl (space group (mce). The color-coding refers to the color of the contacts in Figure 9.

\begin{tabular}{cccc}
\hline $\begin{array}{c}\text { Symmetry Independent } \\
\text { Alkali Metal }\end{array}$ & Wyckoff Letter & $\begin{array}{c}\text { Number of T1 Neighbors } \\
\text { (Distances Below) }\end{array}$ & $\begin{array}{c}\text { Number of K Neighbors } \\
\text { (Distances Below) }\end{array}$ \\
\hline K1 & $8 e$ & $4(<3.8 \AA)$ & $6(<4.3 \AA)$ \\
& & $+2(<4.7 \AA)$ & $+4(<4.8 \AA)$ \\
K2 & $8 d$ & $6(<4 \AA)$ & $4(<4.2 \AA)$ \\
& & $+2(<5.0 \AA)$ & $+4(<4.8 \AA)$ \\
K3 & $8 f$ & $7(<4.1 \AA)$ & $6(<4.4 \AA)$ \\
& & & $+2(<4.7 \AA)$ \\
\hline
\end{tabular}

Table 11. Surrounding atoms of the symmetry inequivalent alkali metal positions in CsTl (space group Fddd). The color-coding refers to the color of the contacts in Figure 9.

\begin{tabular}{|c|c|c|c|}
\hline $\begin{array}{c}\text { Symmetry Independent } \\
\text { Alkali Metal }\end{array}$ & Wyckoff Letter & $\begin{array}{l}\text { Number of T1 Neighbors } \\
\text { (Distances Below) }\end{array}$ & $\begin{array}{c}\text { Number of Cs neighbors } \\
\text { (Distances Below) }\end{array}$ \\
\hline Cs1 & $16 e$ & $\begin{array}{r}4(<4.3 \AA) \\
+2(<4.7 \AA)\end{array}$ & $\begin{array}{r}2(<4.4 \AA) \\
+6(<5.2 \AA)\end{array}$ \\
\hline Cs2 & $16 e$ & $6(<4.3 \AA)$ & $\begin{array}{l}2(<4.2 \AA) \\
+6(<5 \AA)\end{array}$ \\
\hline Cs3 & $16 f$ & $\begin{array}{c}5(<4 \AA) \\
+2(<4.7 \AA)\end{array}$ & $\begin{array}{r}5(<4.4 \AA) \\
+2(<5.2 \AA)\end{array}$ \\
\hline
\end{tabular}

Figure 9 shows the surroundings of the symmetry inequivalent alkali metals in ATl $(\mathrm{A}=\mathrm{Li}, \mathrm{Na}$, $\mathrm{K}, \mathrm{Cs})$, thereby, the shorter distances are given in red, the longer are colored blue. According to the $\beta$-brass type structure, the altogether number of neighboring atoms of $\mathrm{Li}$ in LiTl sums up to 14, of which $8 \mathrm{Tl}$ atoms are at short distances below $3 \AA$ in a cubic arrangement. Six additional coordinating atoms are found at a Li-Li distance of $3.5 \AA$, which is significantly elongated, compared to the Li-Li distance of $3 \AA$ in the bcc unit cell of elemental Lithium [61]. 

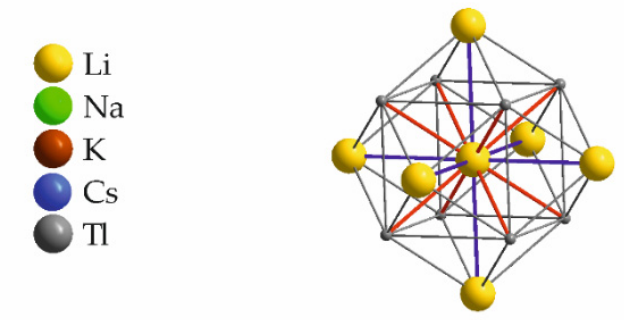

Li1 in LiTl

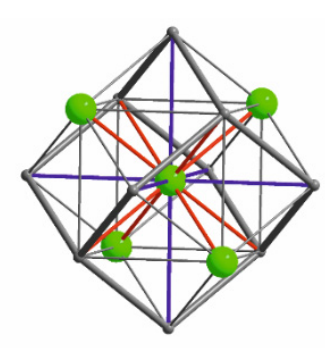

$\mathrm{Na} 1$ in NaTl

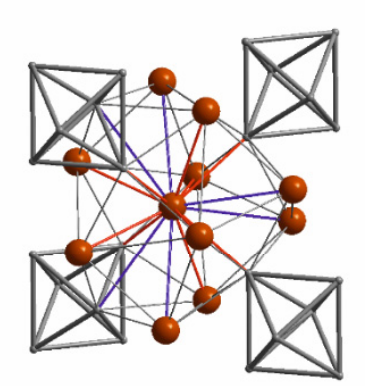

$\mathrm{K} 1$ in KT1

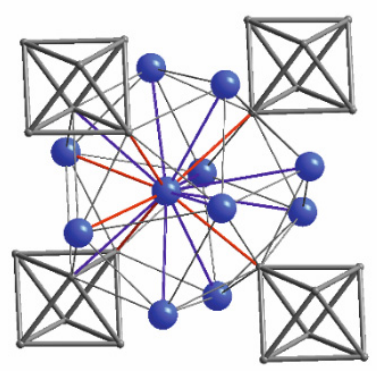

Cs1 in CsTl

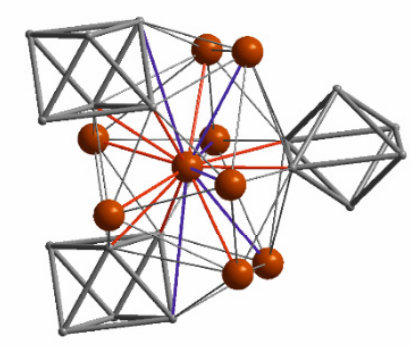

$\mathrm{K} 2$ in KT1

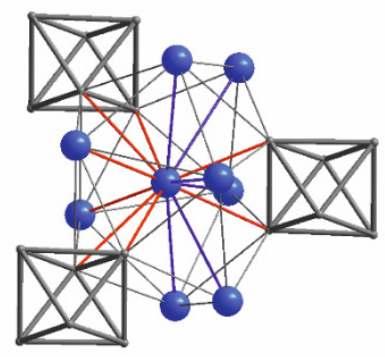

Cs2 in CsTl

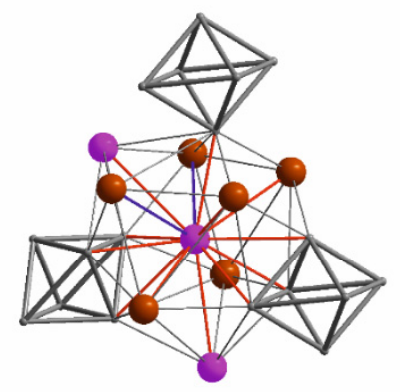

K3 in KT1

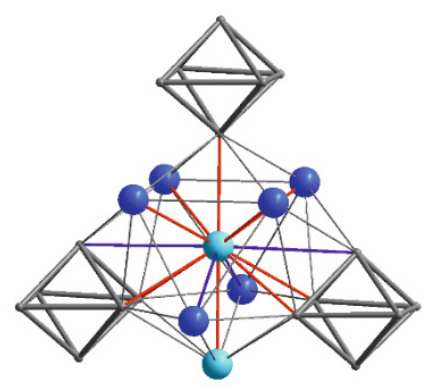

Cs3 in CsTl

Figure 9. Atomic environment of the symmetry inequivalent alkali metals in crystal structures of binary $\operatorname{ATl}(\mathrm{A}=\mathrm{Li}, \mathrm{Na}, \mathrm{K}, \mathrm{Cs})$ at ambient conditions. The corresponding range of distances to the adjacent atoms as well as the Wyckoff letters are given in Tables 8-11. Shorter contacts are colored red, longer distances are given in blue. The color coding is also used in the corresponding tables. K3 and Cs3 are depicted in pink (K3) and cyan (Cs3) within their surroundings to illustrate the K3 zig-zag chains and Cs3 dumbbells.

Na1 in NaTl shows eight contacts at a short distance below $3.3 \AA$, four to $\mathrm{Tl}$ and four to sodium. Additionally, six contacts to thallium at an elongated $\mathrm{Na}-\mathrm{Tl}$ distance of $3.8 \AA$ are present. This interaction was shown to be responsible for the tetragonal distortion of $\mathrm{NaTl}$ at lower temperatures [52]. Altogether, there are 14 neighbors of sodium.

In KTl, each potassium atom is surrounded by 16 (for $\mathrm{K} 1$ and $\mathrm{K} 2$ ) or 15 (for K3) atoms. In general, two sets can be distinguished. Distances belonging to set one are found up to $4.4 \AA$, whereas the distances of set two are significantly elongated up to $5 \AA$. The three alkali metal sites can be differentiated, as there are six distances elongated for K1 and K2 and only two for K3.

Corbett et al. discuss in their publication about CsT1 [58] the two striking positions of Cs3 in CsT1 and $\mathrm{K} 3$ in $\mathrm{KTl}$ more in detail. Both $\mathrm{Cs} 3$ and $\mathrm{K} 3$ connect $\mathrm{Tl}_{6}{ }^{6-}$ units in an unusual way by forming pairs of Cs3 (cyan colored in the surrounding of Cs3 in Figure 9) and chains of K3 (pink colored in the surrounding of K3 in Figure 9). The symmetry operations of the respective space groups is reflected within this arrangement. In CsTl, the regular arrangement of the $\mathrm{Tl}_{6}{ }^{6-}$ units around the Cs3 dimer is described by a twofold axis of space group Fddd. Cs3 and T12 (Wyckoff 16e) are both 
part of the same twofold axis. K3 and T12 (apical atom of the octahedron) have a mirror plane of space group Cmce in common, which therefore makes this symmetry element also part of the $\mathrm{Tl}_{6}{ }^{6-}$ units. The more flexible array of $\mathrm{Tl}_{6}{ }^{6-}$ units in CsTl, obviously is needed for an effective packing. Interestingly, the surroundings of $\mathrm{K} 1 / \mathrm{Cs} 1$ and $\mathrm{K} 2 / \mathrm{Cs} 2$ are very much alike.

In fact, the surroundings of $\mathrm{K} 3$ in $\mathrm{KTl}$ and $\mathrm{Cs} 3 \mathrm{in} \mathrm{CsTl}$ are also very similar, but in $\mathrm{KTl}$ an additional potassium is present compared to the surrounding of Cs3 in CsTl. This additional potassium cation in the coordination sphere of $\mathrm{K} 3$ obviously is needed due to packing requirements.

The existence of $\mathrm{KTl}$ and CsTl makes the absence of any 1:1 compound in the $\mathrm{Rb}-\mathrm{Tl}$ system peculiar. It was suggested that this might be due to the inability of forming an intermediate structure between $\mathrm{KTl}$ and CsTl, or due to the enormous stability of the $\mathrm{Rb}_{8} \mathrm{Tl}_{11}$ phase.

In general, in case of innocent alkali metals and exclusive dominant effects of covalent interactions according to the Zintl-Klemm formalism, one would expect similar structures concerning the Tl-Tl sublattice type for all 1:1 compounds. Theoretical investigations of Miller et al. strongly support the dominant effects of size of the alkali metals on the formed thallide substructure [24].

Summarized, according to Corbett et al. the $\mathrm{Li}-\mathrm{Tl}$ distances in LiTl would be too long in the NaTl type structure, therefore, the formation of $\beta$-brass type LiTl is favored. The stuffed diamond structure of $\mathrm{NaTl}$ is the preferred structure type due to very similar sized sodium/thallium atoms resulting in efficient interwoven three-dimensional thallium and sodium networks. The larger cations potassium and cesium would mean too large Tl-Tl distances when a three-dimensional network would be realized, therefore cluster formation is favored. In general, the ATl series nicely allows for the discussion of differences due to size and electronic effects, but it also was emphasized that these effects are not sufficient for the occurrence of a phase.

The different structure types for 1:1 alkali metal thallides gave rise to deeper investigations by Evers et al. who could show a pressure induced formation of NaTl-type KTl [62]. This result also nicely supports the argumentation of Corbett et al. concerning observed Tl-Tl distances and effective packing.

\section{2. $\mathrm{Na}_{9} \mathrm{~K}_{16} \mathrm{Tl}_{25.25}$}

In the area of similar amounts of alkali metal and thallium (VEC 2) also ternary compounds are reported.

In $\mathrm{Na}_{9} \mathrm{~K}_{16} \mathrm{Tl}_{25.25}$ [63] the $\mathrm{VEC}_{\text {Zintl }}=3.99$ is very close to the previously discussed binary compounds. The thallium substructure includes pentagonal bipyramidal $\mathrm{Tl}_{7}{ }^{7-}$ anions, additional one thallium position with a reduced occupancy of $70 \%$ complements this pentagonal bipyramidal cluster by forming a nine atom $\mathrm{Tl}_{9}{ }^{9-}$ cluster anion. This gives a 70:30 mixture of $\mathrm{Tl}_{9}$ and $\mathrm{Tl}_{7}$ units at the same site, which is necessary to meet the given electron count of the alkali metals. Three fully occupied $\mathrm{Tl}_{9}{ }^{9-}$ clusters would give the fictitious composition $(\mathrm{Na}, \mathrm{K})_{27} \mathrm{Tl}_{27}$ of which the synthesis has failed. To meet the given alkali metal count, which seems to be a structure-determining factor, less thallium is assembled. This makes it worth having a closer look at the alkali metal positions and their surroundings. The asymmetric unit of $\mathrm{Na}_{9} \mathrm{~K}_{16} \mathrm{Tl}_{25.25}$ (space group $P 6_{3} / \mathrm{m}$ ) contains two sodium and five potassium positions (Table 12, Figure 10). Each sodium atom is surrounded by 12 atoms, at distances up to $4.2 \AA$ to potassium and up to $3.5 \AA$ to thallium. The available space around sodium is very limited and probably makes the formation of a binary compound unfavored, when exclusively potassium is included. The binary phases preferably form other, more stable structure types. In $\mathrm{Na}_{9} \mathrm{~K}_{16} \mathrm{Tl}_{25.25}$, the major differences in the surroundings of the symmetry inequivalent potassium positions are found in the farther surroundings. The environment of $\mathrm{K} 1$ (Wyckoff $2 d$ ) is completed by six K4 atoms at a large distance of 4.514(4) $\AA$. K1 also is the only alkali metal without sodium neighboring atoms. The large anisotropic displacement parameter of $\mathrm{K} 5$ was supposed to be caused by the large void around $\mathrm{K} 5$. In general, the possibility of replacing potassium by rubidium was mentioned by Corbett et al., the sodium cavities in contrast seem to be delimitated to small guests. 
Table 12. Surrounding atoms of the symmetry inequivalent alkali metal positions in $\mathrm{Na}_{9} \mathrm{~K}_{16} \mathrm{Tl}_{25.25}$ (space group $P 6_{3} / m$ ). The color-coding refers to the color of the contacts in Figure 10.

\begin{tabular}{ccccc}
\hline $\begin{array}{c}\text { Symmetry } \\
\text { Independent } \\
\text { Alkali Metal }\end{array}$ & $\begin{array}{c}\text { Wyckoff } \\
\text { Letter }\end{array}$ & $\begin{array}{c}\text { Number of Na } \\
\text { Neighbors } \\
\text { (Distances Below) }\end{array}$ & $\begin{array}{c}\text { Number of K } \\
\text { Neighbors } \\
\text { (Distances Below) }\end{array}$ & $\begin{array}{c}\text { Number of T1 } \\
\text { Neighbors } \\
\text { (Distances Below) }\end{array}$ \\
\hline $\mathrm{Na} 1$ & $12 i$ & - & $5(<4.2 \AA)$ & $7(<3.5 \AA)$ \\
$\mathrm{Na} 2$ & $6 g$ & - & $6(<4.2 \AA)$ & $6(<3.5 \AA)$ \\
$\mathrm{K} 1$ & $2 d$ & - & $3(<4 \AA)$ & $6(<3.8 \AA)$ \\
$\mathrm{K} 2$ & $6 h$ & $4(<4.1 \AA)$ & $6(<4.3 \AA)$ & $6(<4.3 \AA)$ \\
$\mathrm{K} 3$ & $6 h$ & $4(<4.3 \AA)$ & $5(<4.3 \AA)$ & $8(<4.2 \AA)$ \\
$\mathrm{K} 4$ & $12 i$ & $2(<3.8 \AA)$ & $7(<4.5 \AA)$ & $5(<3.8 \AA)$ \\
$\mathrm{K} 5$ & $6 h$ & $4(<4.2 \AA)$ & $2(<4.3 \AA)$ & $10(<4.2 \AA)$ \\
\hline
\end{tabular}
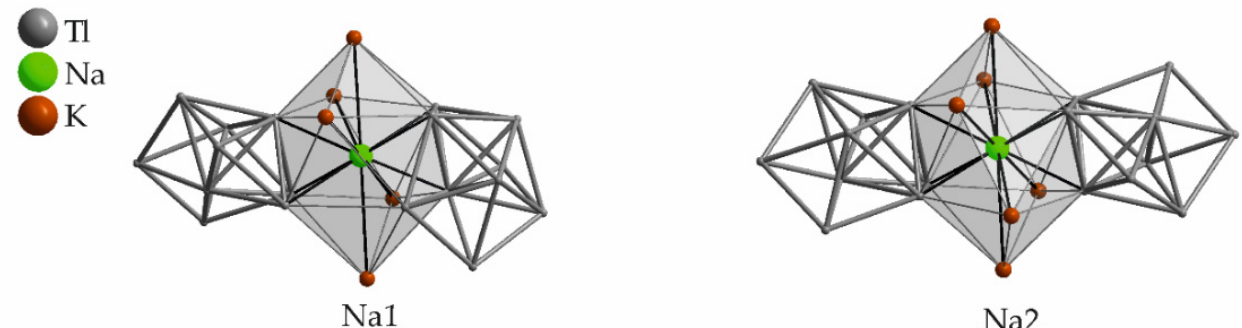

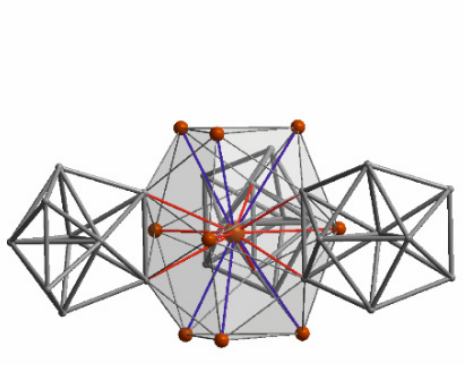

K1

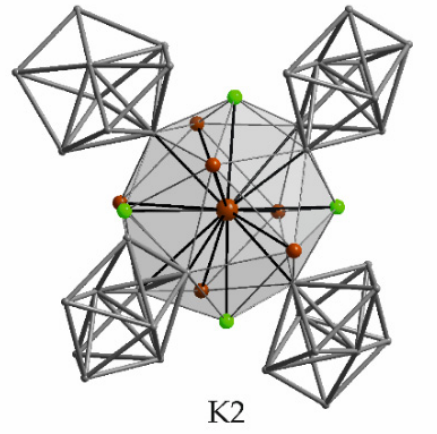

$\mathrm{K} 2$

$$
\mathrm{Na} 2
$$
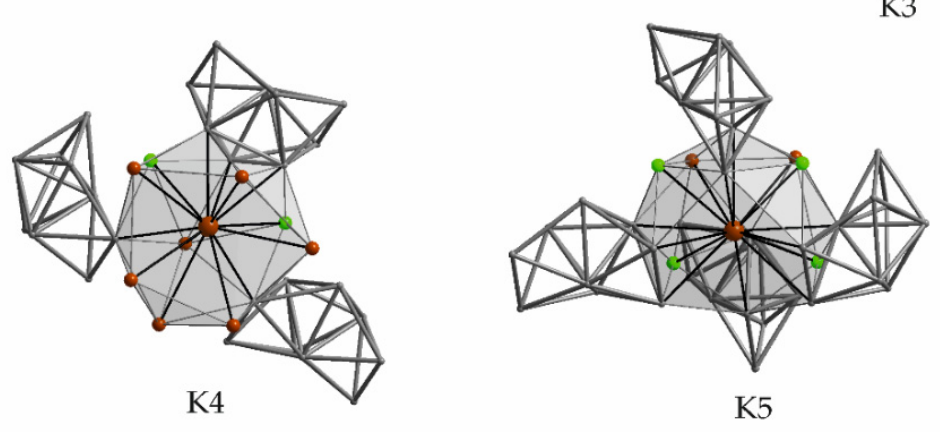

Figure 10. Atomic environment of the symmetry inequivalent sodium and potassium positions in $\mathrm{Na}_{9} \mathrm{~K}_{16} \mathrm{Tl}_{25.25}$. The corresponding range of distances to the adjacent atoms as well as the Wyckoff letters are given in Table 12. Shorter contacts are colored red, longer distances are given in blue, the color coding is also used in the corresponding table (Table 12).

\section{3. $\mathrm{Na}_{2} \mathrm{~K}_{21} \mathrm{Tl}_{19}$}

A slightly increased amount of alkali metal is observed in the compound $\mathrm{Na}_{2} \mathrm{~K}_{21} \mathrm{Tl}_{19}$ [50], which in fact was the first structure where dominant effects of mixed alkali metals could be demonstrated. By supplying more electrons than one per $\mathrm{Tl}$ atom and therefore increasing the $\mathrm{VEC}_{\text {Zintl }}$, the classical 
trigonal bipyramidal shaped thallide cluster $\mathrm{Tl}_{5}{ }^{7-}$ is observed. The shape of $\mathrm{Tl}_{5}{ }^{7-}$ is directly related to isoelectronic $\mathrm{Pb}_{5}{ }^{2-}$. Additionally, the hypoelectronic $\mathrm{Tl}_{9}{ }^{9-}$ anions are present. In the asymmetric unit of the crystal structure (space group $\mathrm{Cmcm}$ ), eight potassium atoms and one sodium are present (Table 13, Figure 11). Sodium is surrounded by ten neighbors, of which five are potassium atoms up to $3.9 \AA$. The remaining five neighbors are represented by thallium up to $3.3 \AA$. At a larger distance of $4.1 \AA$ one additional thallium atom is present, which is in the same range of distance like the second Na-Tl coordination sphere in $\mathrm{NaTl}(\mathrm{d}(\mathrm{Na}-\mathrm{Tl})=3.8 \AA)$. Two additional Tl neighbors are found at distances up to $4.1 \AA$. The resulting overall surrounding resembles the one of $\mathrm{K} 1$, but the void obviously is too small for potassium. Concerning potassium, attentions needs to be drawn at K8, as it turned out to be peculiar in terms of crystallography. Its site occupancy only is $50 \%$, due to the direct vicinity to a mirror plane. Symmetry reduction (space group $C m c 2_{1}$ and $A 2 a m$ ) was checked by the authors and did not result in an ordered model. Lower temperatures $\left(-60^{\circ} \mathrm{C}\right)$ gave only one maximum in the Fourier maps located on the mirror plane, but the large anisotropic displacement parameters still suggested disordering.

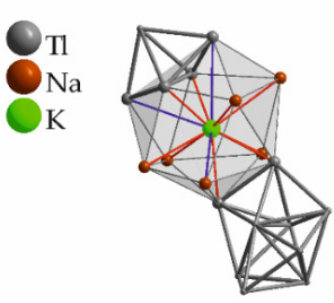

$\mathrm{Na} 1$

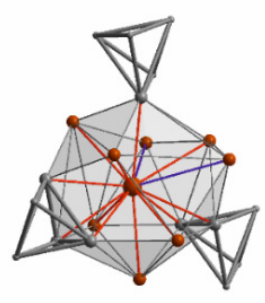

K3

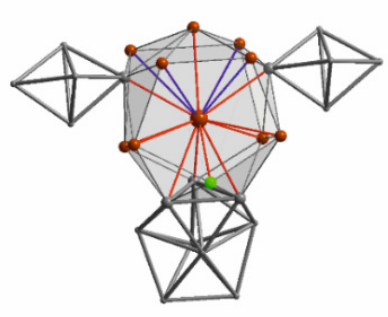

K6

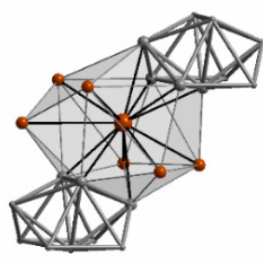

K1

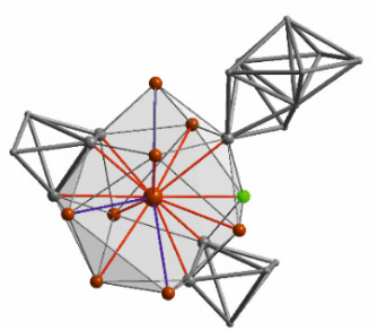

K4

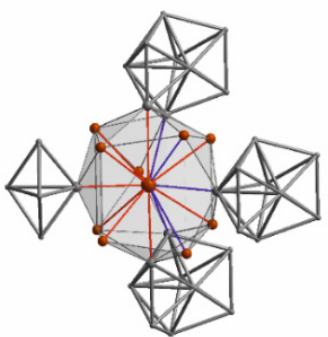

K7

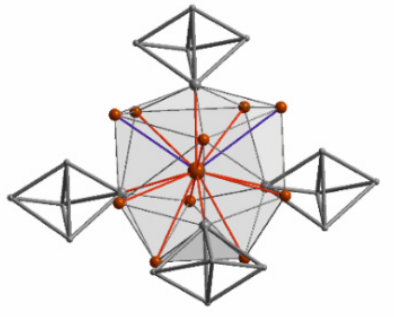

K2

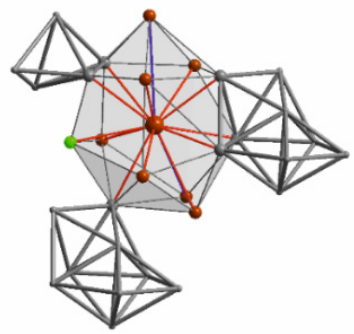

K5

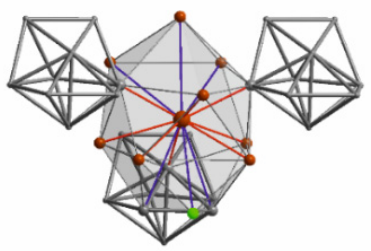

K8

Figure 11. Atomic environment of the symmetry inequivalent sodium and potassium positions in $\mathrm{Na}_{2} \mathrm{~K}_{21} \mathrm{Tl}_{19}$. The corresponding range of distances to the adjacent atoms as well as the Wyckoff letters are given in Table 13. Shorter contacts are colored red, longer distances are given in blue, the color coding is also used in the corresponding table. 
Table 13. Surrounding atoms of the symmetry inequivalent alkali metal positions in $\mathrm{Na}_{2} \mathrm{~K}_{21} \mathrm{Tl}_{19}$ (space group $\mathrm{Cmcm}$ ). The color-coding refers to the color of the contacts in Figure 11.

\begin{tabular}{|c|c|c|c|c|}
\hline $\begin{array}{c}\text { Symmetry } \\
\text { Independent } \\
\text { Alkali Metal }\end{array}$ & $\begin{array}{l}\text { Wyckoff } \\
\text { Letter }\end{array}$ & $\begin{array}{c}\text { Number of } \mathrm{Na} \\
\text { Neighbors } \\
\text { (Distances Below) }\end{array}$ & $\begin{array}{c}\text { Number of K } \\
\text { Neighbors } \\
\text { (Distances Below) }\end{array}$ & $\begin{array}{c}\text { Number of Tl } \\
\text { Neighbors } \\
\text { (Distances Below) }\end{array}$ \\
\hline $\mathrm{K} 1$ & $8 g$ & - & $6(<4.4 \AA)$ & $7(<4 \AA)$ \\
\hline $\mathrm{K} 2$ & $8 f$ & - & $\begin{array}{l}8(<4.5 \AA) \\
+2(<5 \AA)\end{array}$ & $4(<4 \AA)$ \\
\hline K3 & $16 h$ & - & $\begin{array}{l}6(<4.5 \AA) \\
+2(<5 \AA)\end{array}$ & $6(<4 \AA)$ \\
\hline K4 & $16 h$ & $1(<3.8 \AA)$ & $\begin{array}{c}5(<4.3 \AA) \\
+3(<5.1 \AA)\end{array}$ & $6(<4.1 \AA)$ \\
\hline K5 & $16 h$ & $1(<3.6 \AA)$ & $\begin{array}{l}5(<4.5 \AA) \\
+2(<5 \AA)\end{array}$ & $6(<4 \AA)$ \\
\hline K6 & $8 f$ & $1(<3.9 \AA)$ & $\begin{array}{c}5(<4.2 \AA) \\
+4(<5.1 \AA)\end{array}$ & $5(<4 \AA)$ \\
\hline K7 & $8 f$ & - & $\begin{array}{c}7<4.4 \AA) \\
+2(<5 \AA)\end{array}$ & $\begin{array}{c}3(<4.1 \AA) \\
+3(<4.5 \AA)\end{array}$ \\
\hline K8 & $8 f$ & $1(<4.8 \AA)$ & $\begin{array}{c}5<4.2 \AA) \\
+3(<5 \AA)\end{array}$ & $\begin{array}{c}3(<4 \AA) \\
+2(<4.5 \AA)\end{array}$ \\
\hline Na1 & $8 f$ & - & $\begin{array}{c}5(<3.9 \AA) \\
+1(<4.8 \AA)\end{array}$ & $\begin{array}{r}5(<3.3 \AA) \\
+2(<4.1 \AA)\end{array}$ \\
\hline
\end{tabular}

\section{Atomic Ratio $\mathrm{M}^{\mathrm{I}}: \mathrm{Tl}$ Approximately 3:2}

$\mathrm{K}_{10} \mathrm{Tl}_{7}$

The composition of $\mathrm{K}_{10} \mathrm{Tl}_{7}$ [64] is unique for potassium as in this area of VEC no other alkali metal thallide is known so far. $\mathrm{K}_{10} \mathrm{Tl}_{7}$ also represents the potassium-richest binary thallide phase. The included polyanionic species is, according to $\mathrm{MO}$ (molecular orbital) extended Hückel calculations, represented by a pentagonal bipyramidal, hypocloso $\mathrm{Tl}_{7}{ }^{7-}$ anion. Additionally, three extra electrons are present which allow for the favored composition for an effective packing of $\mathrm{Tl}_{7}{ }^{7-}$ anions and potassium cations. The geometry of the anion is close to $D_{5 h}$, the crystallographic symmetry is $C_{1}$ as all atoms lie on general positions of the space group $P 2_{1} / c$. The potassium atoms are also located on general positions around this anion. The number of surrounding atoms and the respective distances of the potassium atoms are given in Table 14. The coordination numbers are between 11 and 15, if distances up to $5 \AA$ are taken into account. At farther distances up to $5.5 \AA$, the coordination number is 13 to 15 . The potassium atoms can be subdivided into two groups concerning their role in the overall crystal structure. Six cations (red: K2, K3, K4, K6, K7, and K10) connect the clusters to form layers, while the remaining (pink: $\mathrm{K} 1, \mathrm{~K} 5, \mathrm{~K} 8$, and $\mathrm{K} 9$ ) are situated between these layers and connect them to form a three-dimensional network (Figure 12). The surroundings of all ten symmetry inequivalent potassium atoms are given in Figure 12. The coloring of the contacts refers to the given range of distances in Table 14. The perceivable surrounding of $\mathrm{K} 3$ is worth mentioning, as 15 neighbors at comparably small distances $(6 \times \mathrm{K}-\mathrm{Tl}(<4 \AA) ; 9 \times \mathrm{K}-\mathrm{K}(<4.7 \AA))$ form the smallest cavity within the crystal structure of $\mathrm{K}_{10} \mathrm{Tl}_{7}$. 
Table 14. Surrounding atoms of the symmetry inequivalent alkali metal positions in $\mathrm{K}_{10} \mathrm{Tl}_{7}$ (space group $P 2_{1} / c$ ). The color-coding refers to the color of the contacts in Figure 12.

\begin{tabular}{|c|c|c|c|}
\hline $\begin{array}{c}\text { Symmetry Independent } \\
\text { Alkali Metal }\end{array}$ & Wyckoff Letter & $\begin{array}{l}\text { Number of K Neighbors } \\
\text { (Distances Below) }\end{array}$ & $\begin{array}{l}\text { Number of Tl Neighbors } \\
\text { (Distances Below) }\end{array}$ \\
\hline K1 & $4 e$ & $\begin{array}{r}8(<4.7 \AA) \\
+2(<5.5 \AA)\end{array}$ & $4(<3.9 \AA)$ \\
\hline K2 & $4 e$ & $\begin{array}{r}8(<4.7 \AA) \\
+1(<5.5 \AA)\end{array}$ & $5(<4.0 \AA ̊)$ \\
\hline K3 & $4 e$ & $9(<4.7 \AA)$ & $6(<4.0 \AA)$ \\
\hline K4 & $4 e$ & $\begin{array}{r}9(<4.7 \AA) \\
+1(<5.5 \AA)\end{array}$ & $4(<4.0 \AA)$ \\
\hline K5 & $4 e$ & $\begin{array}{r}8(<4.7 \AA) \\
+3(<5.5 \AA)\end{array}$ & $3(<4.0 \AA)$ \\
\hline K6 & $4 e$ & $\begin{array}{r}8(<4.7 \AA) \\
+1(<5.5 \AA)\end{array}$ & $5(<4.0 \AA)$ \\
\hline K7 & $4 e$ & $\begin{aligned} 8(<4.5 \AA) \\
+2(<5.5 \AA)\end{aligned}$ & $4(<4.0 \AA)$ \\
\hline K8 & $4 e$ & $\begin{array}{r}8(<4.7 \AA) \\
+3(<5.5 \AA)\end{array}$ & $3(<4.0 \AA)$ \\
\hline K9 & $4 e$ & $\begin{array}{r}7(<4.7 \AA) \\
+3(<5.5 \AA)\end{array}$ & $\begin{aligned} 3(<4.0 \AA) \\
+1(<4.5 \AA)\end{aligned}$ \\
\hline K10 & $4 e$ & $\begin{array}{r}7(<4.7 \AA) \\
+2(<5.5 \AA)\end{array}$ & $4(<4.0 \AA)$ \\
\hline
\end{tabular}

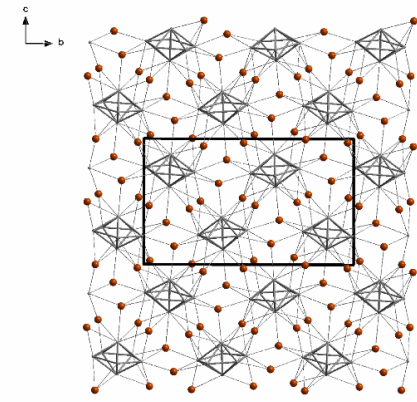

a)

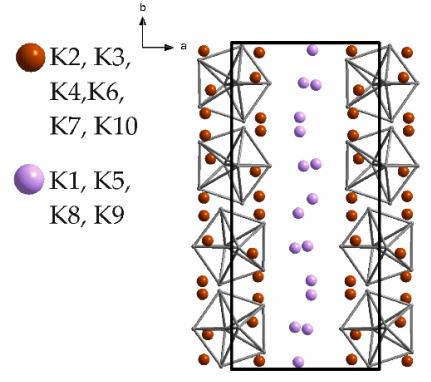

b)

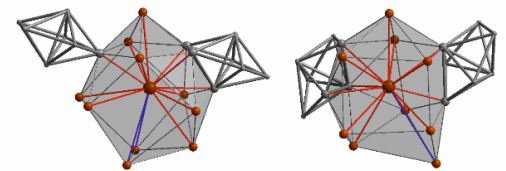

$\mathrm{K} 2$

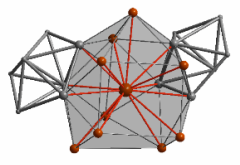

K3

K1

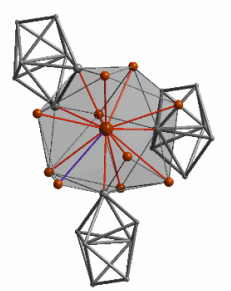

K4

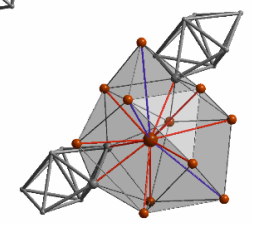

K8

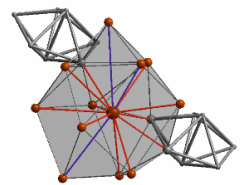

K5

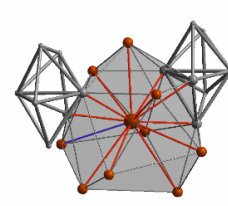

K6

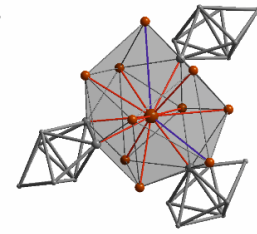

$\mathrm{K} 7$

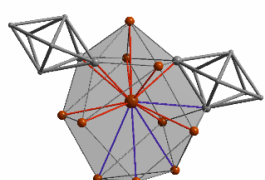

$\mathrm{K} 9$

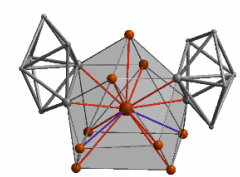

K10

Figure 12. (a) Layers of interconnected, pseudo hexagonal packed $\mathrm{Tl}_{7}{ }^{7-}$ anions (viewing direction along a); (b) unit cell of $\mathrm{K}_{10} \mathrm{Tl}_{7}$, viewing direction along c. Below: Atomic environments of the symmetry inequivalent alkali metals in crystal structures of binary $\mathrm{K}_{10} \mathrm{Tl}_{7}$. The corresponding range of distances to the adjacent atoms as well as the Wyckoff letters are given in Table 14. Shorter contacts are colored red, longer distances are given in blue. The color coding is also used in the corresponding table. 


\section{Atomic Ratio $\mathrm{M}^{\mathrm{I}}: \mathrm{Tl}$ Approximately 2:1}

\section{1. $A_{2} T l(A=L i, N a)$}

At a VEC of 1.67 and $V E C_{Z i n t l}$ of 5, respectively, two compounds are reported. $\mathrm{Li}_{2} \mathrm{Tl}$ [65] crystallizes in the $\mathrm{Li}_{2} \mathrm{Ga}$ type structure and includes $\mathrm{Tl}-\mathrm{Tl}$ zig-zag chains. Both symmetry inequivalent $\mathrm{Li}$ atoms are located at special position $4 c$ of space group $\mathrm{Cmcm}$. The first coordination sphere of both $\mathrm{Li}$ atoms below $3 \AA$ is distorted cubically arranged (red contacts in Figure 10), but the atom type on the vertices differs, as two different interwoven tetrahedral arrangements are built by $\mathrm{Li}$ and $\mathrm{Tl}$, respectively. In the second coordination sphere up to $3.5 \AA$ (blue contacts in Figure 13) one $\mathrm{Tl}$ atom and five $\mathrm{Li}$ atoms are found for Li1, which gives an altogether coordination number (first and second coordination sphere) of 14 for Li1. Li2 is surrounded by six Li and two $\mathrm{Tl}$ in the distorted cubic arrangement. The second coordination sphere is, vice versa to Li1, built by one additional $\mathrm{Li}$ and five additional $\mathrm{Tl}$.

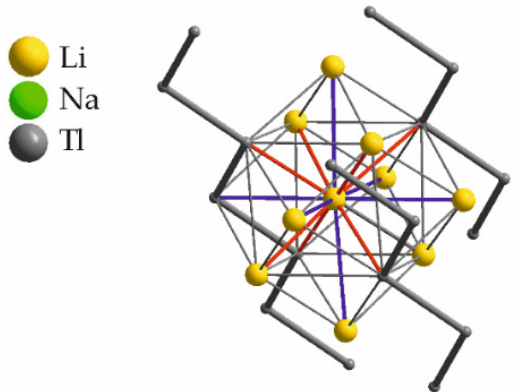

$\mathrm{Li} 1$ in $\mathrm{Li}_{2} \mathrm{Tl}$

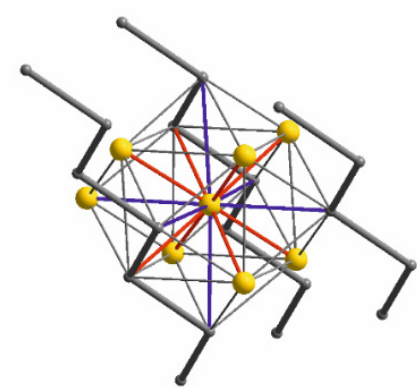

$\mathrm{Li} 2$ in $\mathrm{Li}_{2} \mathrm{Tl}$

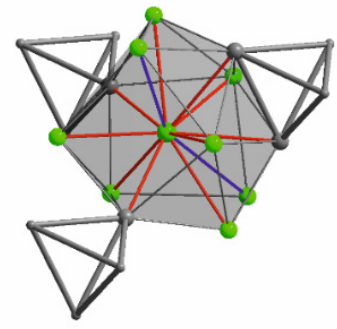

$\mathrm{Na} 1$ in $\mathrm{Na}_{2} \mathrm{Tl}$

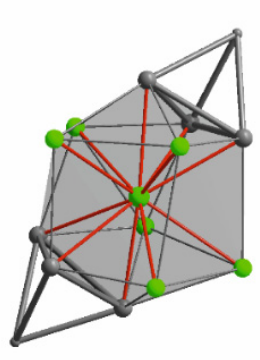

$\mathrm{Na} 2$ in $\mathrm{Na}_{2} \mathrm{Tl}$

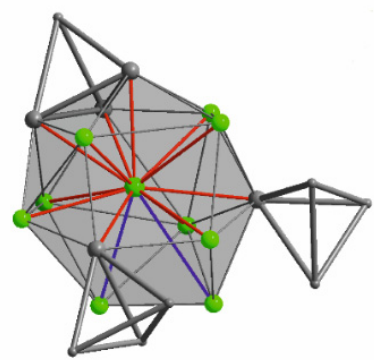

$\mathrm{Na} 3$ in $\mathrm{Na}_{2} \mathrm{Tl}$

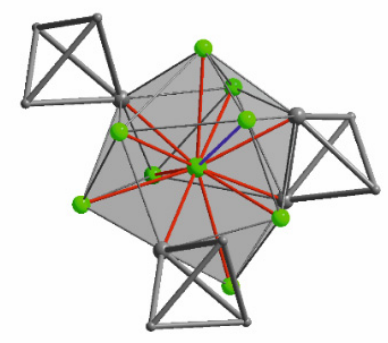

$\mathrm{Na} 4$ in $\mathrm{Na}_{2} \mathrm{Tl}$

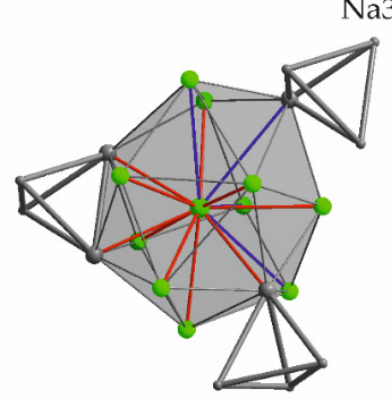

$\mathrm{Na} 5$ in $\mathrm{Na}_{2} \mathrm{Tl}$

Figure 13. Atomic environment of the symmetry inequivalent alkali metals in $\mathrm{Na}_{2} \mathrm{Tl}$. The corresponding range of distances to the adjacent atoms as well as the Wyckoff letters are given in Table 15. Shorter contacts are colored red, longer distances are given in blue. 
Table 15. Surrounding atoms of the symmetry inequivalent alkali metal positions in $\mathrm{Na}_{2} \mathrm{Tl}$ (space group C222 1 ). The color-coding refers to the color of the contacts in Figure 13.

\begin{tabular}{cccc}
\hline $\begin{array}{c}\text { Symmetry Independent } \\
\text { Alkali Metal }\end{array}$ & Wyckoff Letter & $\begin{array}{c}\text { Number of Na Neighbors } \\
\text { (Distances Below) }\end{array}$ & $\begin{array}{c}\text { Number of T1 Neighbors } \\
\text { (Distances Below) }\end{array}$ \\
\hline $\mathrm{Na} 1$ & $4 a$ & $6(<3.7 \AA)$ & $4(<3.5 \AA)$ \\
$\mathrm{Na} 2$ & $4 b$ & $+2(<4.1 \AA)$ & $6(<3.7 \AA)$ \\
$\mathrm{Na} 3$ & $8 c$ & $7(<3.7 \AA)$ & $5(<3.8 \AA)$ \\
& & $9(<3.7 \AA)$ & $4(<3.3 \AA)$ \\
$\mathrm{Na} 4$ & $8 c$ & $7(<3.7 \AA)$ & $3(<3.5 \AA)$ \\
& & $+1(<4.2 \AA)$ & $+1(<4.2 \AA)$ \\
$\mathrm{Na} 5$ & $8 c$ & $6(<3.8 \AA)$ & $+2(<4.2 \AA)$ \\
\hline
\end{tabular}

$\mathrm{Na}_{2} \mathrm{Tl}$ [66] includes classical, tetrahedrally shaped $\mathrm{Tl}_{4}{ }^{8-}$ anions as anionic moiety. $\mathrm{Na}_{2} \mathrm{Tl}$ was the first structurally characterized trielide compound, which contains isolated clusters and therefore represents a milestone in alkali metal trielide chemistry. This result goes back to the works of Hansen in 1967 [66], who was encouraged during his PhD works by J.D. Corbett to perform the structure determination of the latter compound. Tetrahedral shaped anions in solid state structures are well-known in tetrelide chemistry [67], where the binaries of 1:1 stoichiometry form $\mathrm{E}_{4}{ }^{4-}$ anions. The coordination number within the different observed structure types in these cases is 12 (NaGe and $\mathrm{NaSi}$ type) and 16 (KGe and $\mathrm{NaPb}$ type). According to the higher alkali metal content in trielides, the coordination of the $\mathrm{Tl}_{4}{ }^{8-}$ in $\mathrm{Na}_{2} \mathrm{Tl}$ sums up to 23 sodium cations. This very dense packing of alkali metal atoms around the tetrahedra might prevent the formation of a pure binary, when larger congeners of the alkali metals are provided [18]. Having a closer look at the alkali metal positions shows that two of the five symmetry inequivalent sodium atoms are located on special positions $4 a$ and $4 b$ of space group $C 222_{1}$ (Table 15, Figure 13). The remaining three alkali metals reside on general positions. Figure 13 shows the symmetry inequivalent sodium atoms and their local environments, thereby the shorter distances are given in red, longer contacts are colored blue (according to the color-coding in Table 15). 12 to 14 atoms at distances between 3.1 and $4.2 \AA$ surround each sodium atom. The densest surrounding is observed for Na1, as there are 12 distances below $3.7 \AA$ to the adjacent atoms. More space is available for Na5, which only features nine neighbors at shorter distances up to $3.8 \AA$, additional three longer distances up to $4.2 \AA$ A complete the local surrounding.

\section{2. $\mathrm{Na}_{23} \mathrm{Kg}_{9} \mathrm{Tl}_{15.3}$}

At a slight increased $\mathrm{VEC}_{\text {Zintl }}$ of 5.1, the compound $\mathrm{Na}_{23} \mathrm{~K}_{9} \mathrm{Tl}_{15.3}$ [68] could be realized. This compound includes tetrahedral $\mathrm{Tl}_{4}{ }^{8-}$ as well as trigonal bipyramidal $\mathrm{Tl}_{5}{ }^{7-}$ anions. Additionally, a $\mathrm{Tl}_{3}$ trimer is present. This trimer overlaps with an isolated $\mathrm{Tl}^{5-}$ mono-anion. Multiple bonding is discussed for the $\mathrm{Tl}_{3}$ trimer in analogy to higher reduced alkaline earth tetrelide phases, which include tetrelide linear chains [69]. The mixed alkali metals seem to prevent the crystallization of a classical $\mathrm{M}^{\mathrm{I}}: \mathrm{Tl}$ 2:1 stoichiometric compound. Slightly more alkali metal positions are needed for stabilization, which also means an excess of electrons. Therefore, thallium is further reduced under the formation of higher charged thallide species. $\mathrm{Na}_{23} \mathrm{~K}_{9} \mathrm{Tl}_{15.3}$ so far is the alkali-metal-richest thallide phase, where isolated polyanions are present.

The alkali metal positions are very specific, as sodium caps edges and faces of $\mathrm{Tl}_{4}{ }^{8-}$ and $\mathrm{Tl}_{5}{ }^{7-}$, whereas potassium coordinates to the vertices of the clusters (Figure 14, Table 16). Altogether, there are two symmetry inequivalent potassium and five sodium sites. Concerning the sodium environments, one can distinguish between two main surroundings. Na1 and Na3 exhibit 12 neighbors at distances between $3.3 \AA$ and $4.1 \AA$. Na2, Na4, and Na5 feature 13 surrounding atoms between 3.5 and $4.2 \AA$. $\mathrm{Na} 1$ and Na3 are distorted icosahedrally surrounded while $\mathrm{Tl}_{4}{ }^{8-}$ and $\mathrm{Tl}_{5}{ }^{7-}$ clusters are involved. 
For $\mathrm{Na} 2, \mathrm{Na} 4$, and Na5 this icosahedral environment is "disturbed" due to the participation of the $\mathrm{Tl}_{3}$ chain.

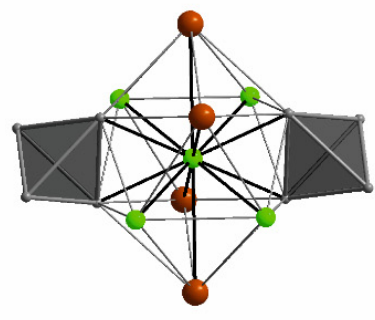

Na1

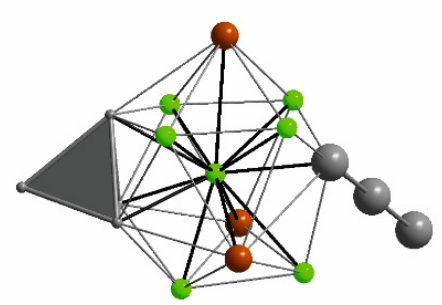

$\mathrm{Na} 2$

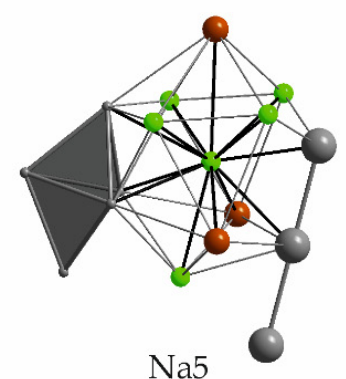

$\mathrm{Na} 5$

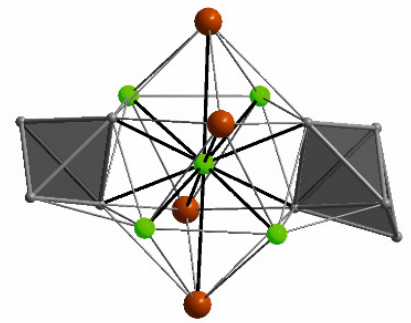

$\mathrm{Na} 3$

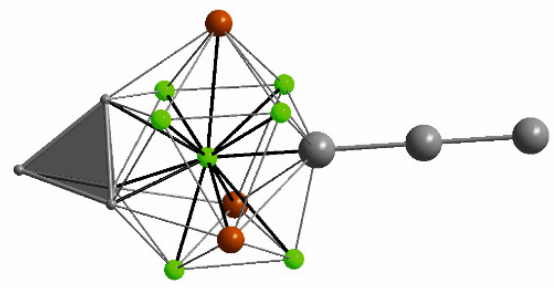

$\mathrm{Na} 4$

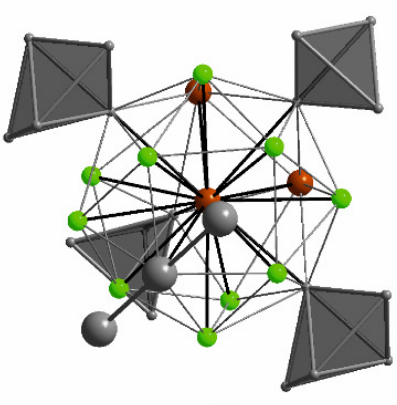

K2

K1

Figure 14. Atomic environment of the symmetry inequivalent alkali metals in $\mathrm{Na}_{23} \mathrm{~K}_{9} \mathrm{Tl}_{15.3}$. The corresponding range of distances to the adjacent atoms as well as the Wyckoff letters are given in Table 16.

Table 16. Surrounding atoms of the symmetry inequivalent alkali metal positions in $\mathrm{Na}_{23} \mathrm{~K}_{9} \mathrm{Tl}_{15.3}$ (space group $\mathrm{P}_{3} / \mathrm{mmc}$ ).

\begin{tabular}{ccccc}
\hline $\begin{array}{c}\text { Symmetry } \\
\text { Independent } \\
\text { Alkali Metal }\end{array}$ & $\begin{array}{c}\text { Wyckoff } \\
\text { Letter }\end{array}$ & $\begin{array}{c}\text { Number of Na } \\
\text { Neighbors } \\
\text { (Distances Below) }\end{array}$ & $\begin{array}{c}\text { Number of K } \\
\text { Neighbors } \\
\text { (Distances Below) }\end{array}$ & $\begin{array}{c}\text { Number of T1 } \\
\text { Neighbors } \\
\text { (Distances Below) }\end{array}$ \\
\hline $\mathrm{K} 1$ & $12 k$ & $8(<4.1 \AA)$ & $4(<4.5 \AA)$ & $4(<4.1 \AA)$ \\
$\mathrm{K} 2$ & $6 h$ & $10(<4.2 \AA)$ & $2(<4.2 \AA)$ & $5(<4.1 \AA)$ \\
$\mathrm{Na} 1$ & $6 g$ & $4(<3.6 \AA)$ & $4(<4.1 \AA)$ & $4(<3.5 \AA)$ \\
$\mathrm{Na} 2$ & $12 k$ & $6(<4 \AA)$ & $3(<4.2 \AA)$ & $4(<3.5 \AA)$ \\
$\mathrm{Na} 3$ & $12 k$ & $4(<3.6 \AA)$ & $4(<4.1 \AA)$ & $4(<3.3 \AA)$ \\
$\mathrm{Na} 4$ & $4 f$ & $6(<4.0 \AA)$ & $3(<4.0 \AA)$ & $4(<3.5 \AA)$ \\
$\mathrm{Na} 5$ & $12 k$ & $5(<3.9 \AA)$ & $3(<4.2 \AA)$ & $5(<3.6 \AA)$ \\
\hline
\end{tabular}


The surroundings of both potassium atoms is similar, the main discrepancy is due to the involvement of the $\mathrm{Tl}_{3}$ trimer instead of a sodium atom for K2. Additionally, fewer contacts to potassium and more contacts to sodium are observed for K2 (Figure 14).

\section{Atomic Ratio $M^{\mathrm{I}}: \mathrm{Tl}>2: 1$}

Thallides very rich in alkali metal are only reported for lithium and sodium and in general, a high content of alkali metal increases the complexity of the compounds [70,71]. Lithium compounds crystallize in known intermetallic structure types, interestingly they are isotypic to lithium tetrelides, which emphasizes the subsidiary role of the VEC for phase stability. $\mathrm{Li}_{5} \mathrm{Tl}_{2}$ [72] crystallizes in the $\mathrm{Li}_{5} \mathrm{Sn}_{2}$ structure type and includes $\mathrm{Tl}_{2}$ dimers with a short $\mathrm{Tl}-\mathrm{Tl}$ distances of $3 \AA$. $\mathrm{Li}_{3} \mathrm{Tl}$ [72] $\left(\mathrm{Li}_{3} \mathrm{~Pb}\right.$ type

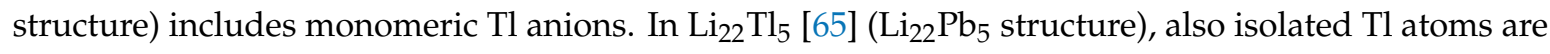
present. The alkali metal thallide with the highest content of alkali metal is found for the complex cubic compound $\mathrm{Na}_{43.8} \mathrm{Tl}_{7}$ (space group F-43m) [73]. The compound includes eleven sodium and three $\mathrm{Tl}$ symmetry inequivalent positions. A topological analysis for $\mathrm{Na}_{44} \mathrm{Tl}_{7}$ was reported by Shevchenko et al. in 2017 [74]. The local environment of ten symmetry independent sodium atoms sums up to 12 atoms, one exception is reported for one sodium position, which only shows nine direct contacts below $4 \AA$.

\section{Comparison of Binary and Ternary Compounds Including Sodium and Potassium}

The number of reported alkali metal thallides is very limited, but the majority involve sodium or potassium. In addition, some ternary compounds are known involving these elements. Table 17 lists alkali metal thallides, which involve sodium and/or potassium. Additionally, the distances are given, up to which a surrounding atom is found in terms of the above described atomic environment. In general, the distances between the alkali metals seem to remain within the same range for binary and ternary materials. Moreover, the $\mathrm{Na}-\mathrm{Tl}$ distances stay the same or at least are little shorter than in the known binaries. In contrast, the $\mathrm{K}-\mathrm{Tl}$ distances attract attention, as they seem to be significantly shifted to smaller values, when sodium is additionally present in the crystal structure. This demonstrates that the impact of mixing sodium and potassium is not only limited to the local environments, but also the overall crystal structure is affected. Of course, this trend is based on data of only a few crystal structures, future ternary compounds will show, if this trend is confirmed or refuted.

Table 17. The comparison of the distances within the hitherto reported alkali metal thallides which involve sodium and/or potassium suggests that an involvement of sodium results in shorter $\mathrm{K}-\mathrm{Tl}$ distances (bold).

\begin{tabular}{cccccc}
\hline Compound & $\mathbf{N a}-\mathbf{T l}$ & $\mathbf{K}-\mathbf{T l}$ & $\mathbf{N a}-\mathbf{N a}$ & $\mathbf{K}-\mathbf{K}$ & $\mathbf{N a}-\mathbf{K}$ \\
\hline $\mathrm{K}_{6} \mathrm{Tl}_{17}$ & - & $<4.8 \AA$ & - & $<4.7 \AA$ & - \\
$\mathrm{K}_{49} \mathrm{Tl}_{108}$ & - & $<4.4 \AA$ & - & $<4.7 \AA$ & - \\
$\mathrm{KTl}$ & - & $<5 \AA$ & - & $<4.8 \AA$ & - \\
$\mathrm{K}_{10} \mathrm{Tl} l_{7}$ & - & $<4.5 \AA$ & - & $<5.5 \AA$ & - \\
\hline $\mathrm{NaTl}$ & $<3.8 \AA$ & - & $<3.3 \AA$ & - & - \\
$\mathrm{Na}_{2} \mathrm{Tl}$ & $<4.2 \AA$ & - & $<4.2 \AA$ & - & - \\
\hline $\mathrm{Na}_{4} \mathrm{~K}_{6} \mathrm{Tl}_{13}$ & $<3.2 \AA$ & $<3.6 \AA$ & - & $<4 \AA$ & $<4.2 \AA$ \\
$\mathrm{Na}_{3} \mathrm{~K}_{8} \mathrm{Tl}_{13}$ & $<3.9 \AA$ & $<3.9 \AA$ & - & $<4.8 \AA$ & $<4.1 \AA$ \\
$\mathrm{Na}_{9} \mathrm{~K}_{16} \mathrm{Tl}_{25.25}$ & $<3.5 \AA$ & $<4.3 \AA$ & - & $<4.5 \AA$ & $<4.3 \AA$ \\
$\mathrm{Na}_{2} \mathrm{~K}_{21} \mathrm{Tl}_{19}$ & $<4.1 \AA$ & $<4.5 \AA$ & - & $<5 \AA$ & - \\
$\mathrm{Na}_{23} \mathrm{~K}_{9} \mathrm{Tl}_{15.3}$ & $<3.6 \AA$ & $<4.1 \AA$ & $<4 \AA$ & $<4.5 \AA$ & $<4.1 \AA$ \\
\hline
\end{tabular}

\section{Conclusions}

The size and nature of the alkali metals play an important role in structure formation of alkali metal thallides, which goes far beyond a classical counter cation, respectively filling atom in 
terms of reasonable numbers for the VEC. The analyses of the local surroundings of the different crystallographic sites on which the alkali metals reside, clearly show discrepancies, even in binary compounds. $\mathrm{Rb}_{14} \mathrm{CsTl}_{27}$ proves that an ordered substitution of one position in a structure type can be realized if different sized voids are available in the respective crystal structure. In contrast, the surrounding of only one alkali metal is supposed to be responsible for the change in the overall crystal structure of $\mathrm{KTl}$ and $\mathrm{CsTl}$, respectively. In the ternary compounds $\mathrm{Na}_{4} \mathrm{~A}_{6} \mathrm{Tl}_{13}(\mathrm{~A}=\mathrm{K}, \mathrm{Rb}, \mathrm{Cs})$, $\mathrm{Na}_{3} \mathrm{~K}_{8} \mathrm{Tl}_{13}, \mathrm{Na}_{9} \mathrm{~K}_{16} \mathrm{Tl}_{25.25}, \mathrm{Na}_{2} \mathrm{~K}_{21} \mathrm{Tl}_{19}$ and $\mathrm{Na}_{23} \mathrm{~K}_{9} \mathrm{Tl}_{15.3}$ the size dependent arrangement and impact on the overall crystal structure could be demonstrated by Corbett et al.

The analyses of the different surroundings of the alkali metal sites in the binary compounds also emerges continuative potential. This is especially interesting, where obviously a disruption concerning formed structure types is given. For example, $\mathrm{K}_{49} \mathrm{Tl}_{108}$ is only known for potassium, whereas at a similar VEC $\mathrm{A}_{15} \mathrm{Tl}_{27}(\mathrm{~A}=\mathrm{Rb}, \mathrm{Cs})$ is reported. The question arises, if the compounds $\mathrm{K}_{15} \mathrm{Tl}_{27}$ or $\mathrm{Rb}_{49} \mathrm{Tl}_{108}$ exist or if the formed structure type is unique for potassium respectively rubidium/cesium. An approach could be the employment of mixed alkali metals in order to prove, if there are site preferences and if yes, which alkali metal on which site is essential for structure formation. A similar approach is conceivable for all unique thallide compounds in order to introduce heavier or lighter alkali metals. This procedure might also allow approximating still unknown $\mathrm{RbTl}$ or heavier congeners of $\mathrm{K}_{10} \mathrm{Tl}_{7}$ or $\mathrm{Na}_{2} \mathrm{Tl}$. The involvement of lithium in ternary compounds has not yet been reported at all and seems to be very promising, especially in combination with the heavier alkali metals $\mathrm{K}, \mathrm{Rb}$ and $\mathrm{Cs}$, as for lithium even smaller voids can be realized.

Of course, directed synthesis based on size effects would be very desirable, but is essentially impossible due to effects other than size (e.g., electronic or thermodynamic). Nevertheless, in virtue of J. D. Corbett: "First comes the synthesis", unknown alkali metal thallides might be observed when more than one alkali metal is provided at a certain VEC. This accounts for a deeper understanding of the role of the alkali metals on the structure formation of alkali metal thallides. Investigative works within the vacant areas of the map of hitherto reported compounds (Figure 1) might provide new insights for this class of materials. With brighter X-ray sources and highly resolving detector techniques this might now be the time to readopt the characterization of these compounds including also the heavier congeners of the alkali metals, which in combination with thallium naturally possess very high absorption coefficients. In conclusion, the structural chemistry of alkali metal thallides still provides exciting aspects even more than 90 years after the very meticulous structural characterization of $\mathrm{NaTl}$ by Eduard Zintl.

Funding: This research received no external funding.

Conflicts of Interest: The author declares no conflict of interest.

\section{References}

1. Zintl, E.; Dullenkopf, W. Über den Gitterbau von NaTl und seine Beziehung zu den Strukturen des Typus des $\beta$-Messings. Z. Phys. Chem. 1932, B16, 195-205. [CrossRef]

2. Hume-Rothery, W. Researches on the Nature, Properties, and Conditions of Formation of Intermetallic Compounds, with special Reference to certain compounds of Tin. J. Inst. Met. 1926, 35, 295-361.

3. Westgren, A.; Phragmen, G. X-Ray Studies on Alloys. Trans. Farad. Soc. 1929, 25, 379-385. [CrossRef]

4. Nesper, R. The Zintl-Klemm Concept-A Historical Survey. Z. Anorg. Allg. Chem. 2014, 640, $2639-2648$. [CrossRef]

5. Pöttgen, R.; Johrendt, D. Intermetallics, 2nd ed.; deGruyter: Berlin, Germany, 2019; pp. 117-122.

6. Laves, F. Eduard Zintls Arbeiten über die Chemie und Struktur von Legierungen. Naturwissenschaften 1941, 29, 244-255. [CrossRef]

7. Häussermann, U.; Amerioun, S.; Eriksson, L.; Lee, C.S.; Miller, G.J. The s-p bonded representatives of the prominent $\mathrm{BaAl}_{4}$ structure type: A case study on structural stability of polar intermetallic network structures. J. Am. Chem. Soc. 2002, 124, 4371-4383. [CrossRef] 
8. Zintl Phases_Principles and Recent Developments; Fässler, T.F. (Ed.) Springer: Berlin/Heidelberg, Germany, 2011; Volume 139.

9. Chemistry, Structure and Bonding of Zintl Phases and Ions; Kauzlarich, S.M. (Ed.) VCH Publishers, Inc.: New York, NY, USA; Weinheim, Germany; Cambridge, UK, 1996.

10. Kauzlarich, S.M. Special Issue: Advances in Zintl Phases. Materials 2019, 12, 2554. [CrossRef]

11. Gärtner, S.; Korber, N. 1.09-Zintl Anions. In Comprehensive Inorganic Chemistry II, 2nd ed.; Reedijk, J., Poeppelmeier, K., Eds.; Elsevier: Amsterdam, The Netherlands, 2013; pp. 251-267.

12. Gärtner, S.; Korber, N. Polyanions of Group 14 and Group 15 Elements in Alkali and Alkaline Earth Metal Solid State Compounds and Solvate Structures. In Zintl Ions Principles and Recent Developments; Fässler, T.F., Ed.; Springer-Verlag: Berlin Heidelberg, Germany, 2011; Volume 140, pp. 25-56.

13. Scharfe, S.; Kraus, F.; Stegmaier, S.; Schier, A.; Fässler, T.F. Zintl Ions, Cage Compounds, and Intermetalloid Clusters of Group 14 and Group 15 Elements. Angew. Chem. Int. Ed. 2011, 50, 3630-3670. [CrossRef]

14. Eisenmann, B.; Cordier, G. Structural Patterns of Homo-and Heteronuclear Anions in Zintl Phases and Related Intermetallic Compounds and Concepts for Their Interpretation. In Chemistry, Structure and Bonding of Zintl Phases and Ions; Kauzlarich, S.M., Ed.; VCH Verlagsgesellschaft mbH: Weinheim, Germany, 1996; pp. 61-137.

15. Schäfer, H.; Eisenmann, B.; Müller, W. Zintl Phases-Transitions between metallic and ionic bonding. Angew. Chem. Int. Ed. 1973, 12, 694-712. [CrossRef]

16. Wang, F.; Wedig, U.; Prasad, D.; Jansen, M. Deciphering the Chemical Bonding in Anionic Thallium Clusters. J. Am. Chem. Soc. 2012, 134, 19884-19894. [CrossRef]

17. Guloy, A.M. Polar Intermetallics and Zintl Phases along the Zintl Border. In Inorganic Cemistry in Focus III; Wiley-VCH Verlag GmbH \& Co: Weinheim, Germany, 2006.

18. Corbett, J.D. Polyanionic clusters and networks of the early p-element metals in the solid state: Beyond the Zintl boundary. Angew. Chem. Int. Ed. 2000, 39, 670-690. [CrossRef]

19. Sangster, J. The Systems Li-Tl, Na-Tl and K-Tl. J. Phase Equilib. 2018, 39, 74-86. [CrossRef]

20. Thümmel, R.; Klemm, W. Behavior of alkali metals to metals of group III-B. Z. Anorg. Allg. Chem. 1970, 376, 44-63. [CrossRef]

21. Corbett, J.D. Exploratory Synthesis: The Fascinating and Diverse Chemistry of Polar Intermetallic Phases. Inorg. Chem. 2010, 49, 13-28. [CrossRef]

22. Belin, C.; Tillard-Charbonnel, M. Aspects of anionic framework formation. Clustering of p-block elements. Coord. Chem. Rev. 1998, 178, 529-564. [CrossRef]

23. Parthe, E. Valence Electron Rules for Compounds with Tetrahedral Structures and Anionic Tetrahedron Complexes. In Modern Perspectives in Inorganic Crystal Chemistry; Parthe, E., Ed.; Springer: Dordrecht, The Netherlands, 1992; Volume 382, pp. 177-201.

24. Wang, F.; Miller, G.J. Revisiting the Zintl-Klemm Concept: Alkali Metal Trielides. Inorg. Chem. 2011, 50, 7625-7636. [CrossRef]

25. Falk, M.; Röhr, C. Stacking polytypes of mixed alkali gallides/indides $A_{1-2}(\mathrm{Ga} / \mathrm{In})_{3}(\mathrm{~A}=\mathrm{K}, \mathrm{Rb}, \mathrm{Cs})$ : Synthesis, crystal chemistry and chemical bonding. Z. Kristallogr. 2019, 234, 623-646. [CrossRef]

26. Meyer, C.; Falk, M.; Röhr, C. Triel-rich mixed potassium indides/gallides: Ternary variants of binary trielides and the new 3:11 compound $\mathrm{K}_{15} \mathrm{Ga}_{45(2)} \mathrm{In}_{10(2)}$. Acta Crystallogr. 2015, 71, S485. [CrossRef]

27. Flot, D.; Tillard-Charbonnel, M.; Belin, C. Crystal structure of sodium potassium thallide indide, $\mathrm{Na}_{6} \mathrm{~K}_{26} \mathrm{In}_{42-\mathrm{x}}\left(\mathrm{In}_{\mathrm{y}} \mathrm{Tl}_{38-\mathrm{y}}\right)(\mathrm{x}=1.08 ; \mathrm{y}=20.12)$. Z. Kristallogr. NCS 1998, 213, 225-226.

28. Flot, D.; Tillard-Charbonnel, M.; Belin, C. $\mathrm{Na}_{12} \mathrm{~K}_{18} \mathrm{In}_{53} \mathrm{Tl}_{7}$ : A novel mixed In/Tl phase hierarchically related to the C15 Friauf-Laves structure type. Synthesis, crystal and electronic structure. New J. Chem. 1998, 22, 591-598. [CrossRef]

29. Kaskel, S.; Klem, M.T.; Corbett, J.D. Polyatomic clusters of the triel elements. Palladium-centered clusters of thallium in $\mathrm{A}_{8} \mathrm{Tl}_{11} \mathrm{Pd}, \mathrm{A}=\mathrm{Cs}, \mathrm{Rb}, \mathrm{K}$. Inorg. Chem. 2002, 41, 3457-3462. [CrossRef] [PubMed]

30. Dong, Z.C.; Corbett, J.D. $\mathrm{Na}_{14} \mathrm{~K}_{6} \mathrm{Tl}_{18} \mathrm{M}(\mathrm{M}=\mathrm{Mg}, \mathrm{Zn}, \mathrm{Cd}, \mathrm{Hg})$ and $\mathrm{Na}_{13.5} \mathrm{Sm}_{0.5} \mathrm{~K}_{6} \mathrm{Tl}_{18} \mathrm{Na}$ : Novel octahedral and centered icosahedral cluster phases related to the $\mathrm{Mg}_{2} \mathrm{Zn}_{11}$-type structure. Angew. Chem. Int. Ed. 1996, 35, 1006-1009. [CrossRef]

31. Saltykov, V.; Nuss, J.; Jansen, M. $\mathrm{Cs}_{10} \mathrm{Tl}_{6} \mathrm{SiO}_{4}, \mathrm{Cs}_{10} \mathrm{Tl}_{6} \mathrm{GeO}_{4}$, and $\mathrm{Cs}_{10} \mathrm{Tl}_{6} \mathrm{SnO}_{3}$-First Oxotetrelate Thallides, Double Salts Containing “Hypoelectronic" $\mathrm{Tl}_{6}{ }^{6-}$ Clusters. Z. Anorg. Allg. Chem. 2011, 637, 1163-1168. [CrossRef] 
32. Saltykov, V.; Nuss, J.; Wedig, U.; Jansen, M. Regular $\mathrm{Tl}_{6}{ }^{6-}$ Cluster in $\mathrm{Cs}_{4} \mathrm{Tl}_{2} \mathrm{O}$ Exhibiting Closed-Shell Configuration and Energetic Stabilization due to Relativistic Spin-Orbit Coupling. Z. Anorg. Allg. Chem. 2011, 637, 357-361. [CrossRef]

33. Karpov, A.; Jansen, $\mathrm{M} . \mathrm{A}_{10} \mathrm{Tl}_{6} \mathrm{O}_{2}(\mathrm{~A}=\mathrm{K}, \mathrm{Rb})$ cluster compounds combining structural features of thallium cluster anions and of alkali metal sub-oxides. Chem. Commun. 2006, 1706-1708. [CrossRef]

34. Kaskel, S.; Dong, Z.C.; Klem, M.T.; Corbett, J.D. Synthesis and structure of the metallic $\mathrm{K}_{6} \mathrm{Tl}_{17}$ : A layered tetrahedral star structure related to that of $\mathrm{Cr}_{3} \mathrm{Si}$. Inorg. Chem. 2003, 42, 1835-1841. [CrossRef]

35. Dong, Z.C.; Corbett, J.D. $\mathrm{A}_{15} \mathrm{Tl}_{27}(\mathrm{~A}=\mathrm{Rb}, \mathrm{Cs})$ : A structural type containing both isolated clusters and condensed layers based on the $\mathrm{Tl}_{11}$ fragment. Syntheses, structure, properties, and band structure. Inorg. Chem. 1996, 35, 1444-1450. [CrossRef]

36. Häussermann, U.; Svensson, C.; Lidin, S. Tetrahedral stars as flexible basis clusters in sp-bonded intermetallic frameworks and the compound $\mathrm{BaLi}_{7} \mathrm{Al}_{6}$ with the $\mathrm{NaZn}_{13}$ structure. J. Am. Chem. Soc. 1998, 120, 3867-3880. [CrossRef]

37. Cordier, G.; Müller, V.; Fröhlich, R. Crystal structure of potasium thallide (49/108), $\mathrm{K}_{49} \mathrm{Tl}_{108}$. Z. Kristallogr. 1993, 203, 148-149.

38. Cordier, G.; Müller, V. Preparation and crystal structure of $\mathrm{K}_{49} \mathrm{Tl}_{108}$. Z. Naturforsch. B 1993, 48, $1035-1040$. [CrossRef]

39. Müller, V. Darstellung und Kristallstrukturen von Alkalimetall- Erdmetall- und Alkalimetall-Zink-Verbindungen. Ph.D. Thesis, Technische Hochschule Darmstadt, Darmstadt, Germany, 1995.

40. Bullett, D.W. Structure and bonding in crystalline boron and $\mathrm{B}_{12} \mathrm{C}_{3}$. J. Phys. C Solid State Phys. 1982, 15, 415-426. [CrossRef]

41. Hughes, R.E.; Kennard, C.H.L.; Sullenger, D.B.; Weakliem, H.A.; Sands, D.E.; Hoard, J.L. The Structure of $\beta$-Rhombohedral Boron. J. Am. Chem. Soc. 1963, 85, 361-362. [CrossRef]

42. Cordier, G.; Müller, V. Compounds at the Zintl Border-Preparation and Crystal Structure of $\mathrm{Na}_{17} \mathrm{Ga}_{29} \mathrm{In}_{12}$ and $\mathrm{K}_{17} \mathrm{In}_{41}$. Z. Naturforsch. B 1994, 49, 721-728. [CrossRef]

43. Schaefer, M.C.; Bobev, S. Tin Clathrates with the Type II Structure. J. Am. Chem. Soc. 2013, 135, 1696-1699. [CrossRef]

44. Karttunen, A.J.; Fässler, T.F. Structural Principles and Thermoelectric Properties of Polytypic Group 14 Clathrate-II Frameworks. ChemPhysChem 2013, 14, 1807-1817. [CrossRef]

45. Carrillo-Cabrera, W.; Caroca-Canales, N.; Von Schnering, H.G. $\mathrm{K}_{21-\delta} \mathrm{Na}_{2+\delta} \operatorname{In}_{39}(\delta=2.8)-\mathrm{A}$ Cluster-replacement clathrate-II structure with an alkali-metal $\mathrm{M}_{136}$-network. Z. Anorg. Allg. Chem. 1994, 620, 247-257. [CrossRef]

46. Blase, W.; Cordier, G.; Müller, V.; Häussermann, U.; Nesper, R.; Somer, M. Preparation and Crystal-Structures of $\mathrm{Rb}_{8} \mathrm{In}_{11}, \mathrm{~K}_{8} \mathrm{Tl}_{11}$, And $\mathrm{Rb}_{8} \mathrm{Tl}_{11}$ Band-Structure Calculations On $\mathrm{K}_{8} \mathrm{In}_{11}$. Z. Naturforsch. B 1993, 48, 754-760. [CrossRef]

47. Dong, Z.-C.; Corbett, J.D. $\mathrm{A}_{8} \mathrm{Tl}_{11}(\mathrm{~A}=\mathrm{K}, \mathrm{Rb}$, or $\mathrm{Cs})$ Phases with Hypoelectronic $\mathrm{Tl}_{11}{ }^{7-}$ Cluster Anions: Syntheses, Structure, Bonding and Properties. J. Cluster Sci. 1995, 6, 187-201. [CrossRef]

48. Sevov, S.C.; Corbett, J.D. A Remarkable Hypoelectronic Indium Cluster in $\mathrm{K}_{8} \mathrm{In}_{11}$. Inorg. Chem. 1991, 30, 4875-4877. [CrossRef]

49. Gärtner, S.; Tiefenthaler, S.; Korber, N.; Stempfhuber, S.; Hischa, B. Structural Chemistry of Halide including Thallides $\mathrm{A}_{8} \mathrm{Tl}_{11} \mathrm{X}_{1-\mathrm{n}}(\mathrm{A}=\mathrm{K}, \mathrm{Rb}, \mathrm{Cs} ; \mathrm{X}=\mathrm{Cl}, \mathrm{Br} ; \mathrm{n}=0.1-0.9)$. Crystals 2018, 8, 319. [CrossRef]

50. Dong, Z.C.; Corbett, J.D. $\mathrm{Na}_{2} \mathrm{~K}_{21} \mathrm{Tl}_{19}$, a novel thallium compound containing isolated $\mathrm{Tl}_{5}{ }^{7-}$ and $\mathrm{Tl}_{9}{ }^{9-}$ groups-A new hypoelectronic cluster. J. Am. Chem. Soc. 1994, 116, 3429-3435. [CrossRef]

51. Dong, Z.C.; Corbett, J.D. Unusual icosahedral cluster compounds-Open-shell $\mathrm{Na}_{4} \mathrm{~A}_{6} \mathrm{Tl}_{13}(\mathrm{~A}=\mathrm{K}, \mathrm{Rb}, \mathrm{Cs})$ and the metallic Zintl phase $\mathrm{Na}_{3} \mathrm{~K}_{8} \mathrm{Tl}_{13}$ (How does chemistry work in solids). J. Am. Chem. Soc. 1995, 117, 6447-6455. [CrossRef]

52. Tiefenthaler, S.M.; Schlosser, M.; Pielnhofer, F.; Shenderovich, I.G.; Pfitzner, A.; Gärtner, S. Investigations on Tetragonally Distorted Sodium Thallide NaTl-tI8. Z. Anorg. Allg. Chem. 2020, 646, 82-87. [CrossRef]

53. Tiefenthaler, S.; Korber, N.; Gärtner, S. Synthesis of the Tetragonal Phase of Zintl's NaTl and Its Structure Determination from Powder Diffraction Data. Materials 2019, 12, 1356. [CrossRef]

54. Vollmar, E.; Ehrenberg, H.; Baehtz, C.; Knapp, M.; Pauly, H. Temperature-induced phase transitions of the Zintl phase NaTl: The role of sodium deficiency. Hasylab Annu. Rep. 2005, 533-534. 
55. Schneider, J. Cation Short Range Order in non-stoichiometric NaTl. Mat. Science Forum 1988, 27-28, 63-68. [CrossRef]

56. Baden, W.; Schmidt, P.C.; Weiss, A. The intermetallic system $\mathrm{LiCd}_{1-x} \mathrm{Tl}_{\mathrm{X}} \mathrm{X}$-ray investigations and measurements of the Knight shift of ${ }^{205} \mathrm{Tl}$ and ${ }^{113} \mathrm{Cd}$. Phys. State Sol. A 1979, 51, 183-190. [CrossRef]

57. Dong, Z.C.; Corbett, J.D. Synthesis, structure, and bonding of the novel cluster compound KTl with isolated $\mathrm{Tl}_{6}{ }^{6-}$ ions. J. Am. Chem. Soc. 1993, 115, 11299-11303. [CrossRef]

58. Dong, Z.C.; Corbett, J.D. CsTl: A new example of tetragonally compressed $\mathrm{Tl}_{6}{ }^{6-}$ octahedra. Electronic effects and packing requirements in the diverse structures of $\mathrm{ATl}(\mathrm{A}=\mathrm{Li}, \mathrm{Na}, \mathrm{K}, \mathrm{Cs})$. Inorg. Chem. 1996, 35, 2301-2306. [CrossRef]

59. King, R.B.; Silaghi-Dumitrescu, I. The role of "external" lone pairs in the chemical bonding of bare post-transition element clusters: The Wade-Mingos rules versus the jellium model. Dalton Trans. 2008, 44, 6083-6088. [CrossRef]

60. Wade, K. Structural and Bonding Patterns in Cluster Chemistry. Adv. Inorg. Radiochem. 1976, 18, 1-66.

61. Nadler, M.R.; Kempfer, C.P. Crystallographic Data Lithium. Anal. Chem. 1959, 31, 2109. [CrossRef]

62. Evers, J.; Oehlinger, G. After more than 60 years, a new NaTl type Zintl phase: KTl at high pressure. Inorg. Chem. 2000, 39, 628-629. [CrossRef]

63. Li, B.; Corbett, J.D. $\mathrm{Na}_{9} \mathrm{~K}_{16} \mathrm{Tl}_{\sim 25}$ : A new phase containing naked icosahedral cluster fragments $\mathrm{Tl}_{9}{ }^{9-}$. J. Clust. Sci. 2008, 19, 331-340. [CrossRef]

64. Kaskel, S.; Corbett, J.D. Synthesis and structure of $\mathrm{K}_{10} \mathrm{Tl}_{7}$ : The first binary trielide containing naked pentagonal bipyramidal $\mathrm{Tl}_{7}$ clusters. Inorg. Chem. 2000, 39, 778-782. [CrossRef]

65. Stöhr, J.; Müller, W.; Schäfer, H. Structural Principles of Lithium Group III Compounds. Acta Crystallogr. A 1981, 37, C185. [CrossRef]

66. Hansen, D.A.; Smith, J.F. Structure and Bonding Model For Na 2 Tl. Acta Cryst. 1967, 22, 836-845. [CrossRef]

67. Lorenz, C.; Gärtner, S.; Korber, N. Ammoniates of Zintl Phases: Similarities and Differences of Binary Phases $\mathrm{A}_{4} \mathrm{E}_{4}$ and Their Corresponding Solvates. Crystals 2018, 8, 276. [CrossRef]

68. Dong, Z.C.; Corbett, J.D. $\mathrm{Na}_{23} \mathrm{~K}_{9} \mathrm{Tl}_{15.3}$ : An unusual Zintl compound containing apparent $\mathrm{Tl}_{5}{ }^{7-}, \mathrm{Tl}_{4}{ }^{8-}, \mathrm{Tl}_{3}{ }^{7-}$, and $\mathrm{Tl}^{5-}$ anions. Inorg. Chem. 1996, 35, 3107-3112. [CrossRef]

69. Nesper, R.; Wengert, S. $\mathrm{Sr}_{12} \mathrm{Mg}_{17.8} \mathrm{Li}_{2.2} \mathrm{Si}_{20}$, the first Zintl-phase with a $\mathrm{Si}_{3}$ chain. Chem. Mon. 1999, 130, 197-202.

70. Bell, T.; Smetana, V.; Mudring, A.-V.; Meyer, G.H. Binary Intermetallics in the 70 atom \% R Region of Two R-Pd Systems ( $\mathrm{R}=\mathrm{Tb}$ and Er): Hidden, Obscured, or Nonexistent? Inorg. Chem. 2020, 59, 10802-10812. [CrossRef]

71. Ovchinnikov, A.; Smetana, V.; Mudring, A.-V. Metallic alloys at the edge of complexity: Structural aspects, chemical bonding and physical properties. J. Phys. Condens. Matter 2020, 243002. [CrossRef]

72. Stöhr, J.; Schäfer, H. Die Kristallstrukturen von $\mathrm{Li}_{3} \mathrm{In}_{2}, \mathrm{Li}_{5} \mathrm{Tl}_{2}$ und $\mathrm{Li}_{3} \mathrm{Tl}$. Z. Naturforsch. B 1979, 34, $653-656$. [CrossRef]

73. Samson, S.; Hansen, D.A. Complex cubic $\mathrm{A}_{6} \mathrm{~B}$ compounds 1. Crystal structure of $\mathrm{Na}_{6} \mathrm{Tl}$. Acta Crystallogr. B 1972, 28, 930-935. [CrossRef]

74. Shevchenko, V.Y.; Blatov, V.A.; Ilyushin, G.D. Modeling Self-Organization Processes in Crystal Forming Systems. Symmetry and Topology Codes of Cluster Self-Assembly of Crystal Structure of $\mathrm{Na}_{44} \mathrm{Tl}_{7}\left(\mathrm{Na}_{6} \mathrm{Tl}\right)$. Glass Phys. Chem. 2017, 43, 521-529. [CrossRef]

Publisher's Note: MDPI stays neutral with regard to jurisdictional claims in published maps and institutional affiliations.

(C) 2020 by the author. Licensee MDPI, Basel, Switzerland. This article is an open access article distributed under the terms and conditions of the Creative Commons Attribution (CC BY) license (http://creativecommons.org/licenses/by/4.0/). 